\title{
Intralaminar and Interlaminar Activity within the Rodent Superior Colliculus Visualized with Voltage Imaging
}

\author{
Corinne R. Vokoun, ${ }^{1}$ Meyer B. Jackson, ${ }^{2}$ and Michele A. Basso ${ }^{2,3}$ \\ ${ }^{1}$ Molecular and Cellular Pharmacology Training Program, ${ }^{2}$ Department of Physiology, and ${ }^{3}$ Department of Ophthalmology and Visual Sciences, University \\ of Wisconsin, Madison Medical School, Madison, Wisconsin 53706
}

The superior colliculus (SC) is a midbrain structure that plays a role in converting sensation into action. Most SC research focuses on either in vivo extracellular recordings from behaving monkeys or patch-clamp recordings from smaller mammals in vitro. However, the activity of neuronal circuits is necessary to generate behavior, and neither of these approaches measures the simultaneous activity of large populations of neurons that make up circuits. Here, we describe experiments in which we measured changes in membrane potential across the SC map using voltage imaging of the rat SC in vitro. Our results provide the first high temporal and spatial resolution images of activity within the SC. Electrical stimulation of the SC evoked a characteristic two-component optical response containing a short latency initial-spike and a longer latency after-depolarization. Single-pulse stimulation in the superficial SC evoked a pattern of intralaminar and interlaminar spread that was distinct from the spread evoked by the same stimulus applied to the intermediate SC. Intermediate layer stimulation produced a more extensive and more ventrally located activation of the superficial layers than did stimulation in the superficial SC. Together, these results indicate the recruitment of dissimilar subpopulations of circuitry depending on the layer stimulated. Field potential recordings, pharmacological manipulations, and timing analyses indicate that the patterns of activity were physiologically relevant and largely synaptically driven. Therefore, voltage imaging is a powerful technique for the study of spatiotemporal dynamics of electrical signaling across neuronal populations, providing insight into neural circuits that underlie behavior.

\section{Introduction}

The superior colliculus (SC) is a midbrain structure that can be divided into a superficial sensory portion and a deeper somatic portion. This general architecture is evident in all mammals studied and even appears in primitive vertebrates (Kennedy, 1984). Because the SC afferents arise from sensory structures and the SC efferents target lower brainstem and spinal cord motor circuits, it is generally understood that the SC transforms sensory signals into commands for action (Vanegas, 1984; Sparks, 1986). A well studied example of this is orienting behavior in response to visual stimuli. In monkeys, orienting is studied by measuring saccadic eye movements. In lower mammals such as rodents, the orienting behavior often includes movements of the head, neck, and body (Dean et al., 1989). Despite the large differences in visual processing between higher and lower mammals, rodents are able to move their eyes independently, somewhat akin to the behavior of higher mammals (McHaffie and Stein, 1982; Fuller, 1985; Chelazzi et al., 1989; Sakatani and Isa, 2004, 2007; Chalupa and Williams, 2008).

The bulk of what is known about the role of SC in behavior comes from single-neuron, extracellular recording studies in be-

Received March 9, 2010; revised June 21, 2010; accepted June 24, 2010.

This work was supported by the Alice R. McPherson Endowment for the Visual Sciences at the UW Eye Research Institute (to M.A.B. and M.B.J.) and by the Parkinson's Disease Foundation Summer Student Fellowship program (to C.R.V.).

Correspondence should be addressed to Dr. Michele A. Basso, Department of Physiology, University of Wisconsin, Madison, Medical School, 1300 University Ave., Room 127 SM1, Madison, WI 53706. E-mail: michele@ physiology.wisc.edu.

DOI:10.1523/JNEUROSCI.1387-10.2010

Copyright $\odot 2010$ the authors $\quad 0270-6474 / 10 / 3010667-16 \$ 15.00 / 0$ having monkeys. Although powerful, this technique is blind to the activity of large populations of neurons, even though the activity of large populations is thought to determine the vector of the saccade (Schiller and Koerner, 1971; Robinson, 1972; Wurtz and Goldberg, 1972; Sparks, 1975, 1978; Ottes et al., 1986; Van Gisbergen et al., 1987; Lee et al., 1988; Mcllwain, 1991; Quaia et al., 1998; Groh, 2001; Hanes and Wurtz, 2001). Recent investigations implementing multiple-neuron recording techniques in monkeys are exploring how populations of SC neurons contribute to sensorimotor integration (Port and Wurtz, 2003; Kim and Basso, 2008, 2010).

Other recent investigations focus on in vitro, whole-cell patchclamp recordings from rodent SC slices (Isa and Hall, 2009). This approach reveals that the circuitry involved in transforming visual signals into eye movement commands can be preserved within a 300-400 $\mu \mathrm{m}$ slice (Özen et al., 2000; Saito and Isa, 2005; Lee and Hall, 2006). Furthermore, these works suggest that the membrane properties of individual neurons are inadequate to account for specific aspects of their discharge properties, notably the robust bursting of SC output neurons. Thus, synaptic connections appear critical (Özen et al., 2000). Consequently, understanding the mechanisms of sensorimotor integration and the control of eye movements in the SC will require implementing techniques that reveal the biophysical properties of neuronal circuits that underlie these behaviors.

In this report, we describe experiments that use voltage imaging to investigate population activity of the neuronal circuits within rodent SC slices. Stimulation of the superficial SC evoked a distinct pattern of synaptic activity that spread throughout the 
superficial and intermediate layers. Stimulation of the intermediate SC evoked a different pattern. Signal spread at the site of stimulation was spatially restricted, but activity extending into the superficial layers spread widely. Local field potential recordings as well as pharmacological manipulations suggest that the patterns of activity are physiologically relevant and synaptically driven. In addition to confirming results from whole-cell patchclamp experiments, our voltage imaging results show population responses throughout the SC that are highly dynamic and extend great distances spatially.

\section{Materials and Methods}

Slice preparation. Male Sprague Dawley rats (Rattus norvegicus, 3-8 weeks old) were rendered unconscious by inhalation of $\mathrm{CO}_{2}$ and decapitated in accordance with the recommendations of the Panel on Euthanasia of the Veterinary Medical Association and the United States Public Health Service policy on the humane care and use of laboratory animals. All protocols were approved by the School of Medicine Animal Care and Use Committee of the University of Wisconsin-Madison. The brains were quickly removed and chilled in ice-cold cutting solution consisting of the following (mM): $124 \mathrm{NaCl}, 3.2 \mathrm{KCl}, 26 \mathrm{NaHCO}_{3}, 1.25 \mathrm{NaH}_{2} \mathrm{PO}_{4}, 1$ $\mathrm{CaCl}_{2}, 6 \mathrm{MgSO}_{4}, 10$ glucose, and 1.85 kynurenic acid (Sigma-Aldrich), bubbled with $95 \% \mathrm{O}_{2} / 5 \% \mathrm{CO}_{2}$. The brains were blocked to isolate the midbrain and sliced at 350-400 $\mu \mathrm{m}$ with a tissue slicer (HR2, Sigmann Elektronik). Slices were stored in bubbled cutting solution for $30 \mathrm{~min}$ at room temperature $\left(21-24^{\circ} \mathrm{C}\right)$ and then transferred to bubbled artificial CSF (aCSF; identical to cutting solution, but with $2.5 \mathrm{~mm} \mathrm{CaCl}_{2}, 1.3 \mathrm{~mm}$ $\mathrm{MgSO}_{4}$, and no kynurenic acid) at room temperature for 30-60 min. Slices were stained in bubbled aCSF containing $0.05 \mathrm{mg} \mathrm{ml}^{-1}$ of the voltage-sensitive dye RH482 for 30-45 min at room temperature. Experiments were performed at room temperature in a submerged recording chamber superfused with bubbled aCSF.

Electrophysiology. Both electrical stimulation and local field potential recordings were performed with glass capillary electrodes filled with aCSF. Stimulating electrodes had 3-10 $\mu \mathrm{m}$ tips and recording electrodes had $2-5 \mu \mathrm{m}$ tips. Stimulation in the form of a $100 \mu \mathrm{A}, 200 \mu$ s pulse was applied $200 \mathrm{~ms}$ after the start of data acquisition, using a Grass S88 wave pulse generator and two Grass photoelectric stimulus isolation units (Grass Technologies) configured to produce a current-balanced, biphasic pulse. Field potentials were recorded with a patch-clamp amplifier and read into an auxiliary analog input of the imaging data acquisition system.

Voltage imaging. Optical signals were recorded with a 464 channel fiber-optic photodiode system (Wu and Cohen, 1993; Chang and Jackson, 2006). Signals were amplified to $5 \mathrm{~V} \mathrm{nA}^{-1}$ of photocurrent, low-pass filtered at $500 \mathrm{~Hz}$, and digitized at a frame rate of $5 \mathrm{kHz}$ with a DAP 5200 data acquisition board (Microstar Laboratories). The preparation was illuminated from below with a $100 \mathrm{~W}$ tungsten-halogen bulb driven by a Kepco ATE 36-30 DM power supply. Illuminating light passed through a $700 \pm 25 \mathrm{~nm}$ bandpass filter and transmitted light was collected with a $10 \times$ Olympus objective (numerical aperture $=0.4$ ). The center-tocenter distance between adjacent photodiode fields was $\sim 67 \mu \mathrm{m}$. A CCD camera was used to take images for superimposing with optical traces (Fig. 1). All data traces reported were averages of four trials at $10 \mathrm{~s}$ intervals.

Pharmacology. Drugs were applied by exchange of solution bathing slices. 2,3-Dihydroxy-6-nitro-7-sulfamoyl-benzo[f] quinoxaline-7-sulfonamide disodium (NBQX), tetrodotoxin (TTX), (-)bicuculline methiodide, D-(-)amino-5-phosphonovaleric acid (APV), and DL-threo$\beta$-hydroxyaspartic acid were obtained from Sigma-Aldrich. Gabazine hydrobromide (SR-95531) was obtained from either Tocris Bioscience or Sigma-Aldrich.

Data analysis. Data acquisition, signal processing, and some analyses were performed with a computer program written in this laboratory (Chang and Jackson, 2006). Data acquisition parameters, shutter control, and stimulus protocols were specified within the graphical user interface. Images were acquired at $0.2 \mathrm{~ms}$ intervals for $800 \mathrm{~ms}$. A shutter opened $200 \mathrm{~ms}$ before data acquisition and closed immediately after to limit light exposure. Electrical stimulation produced optical signals that

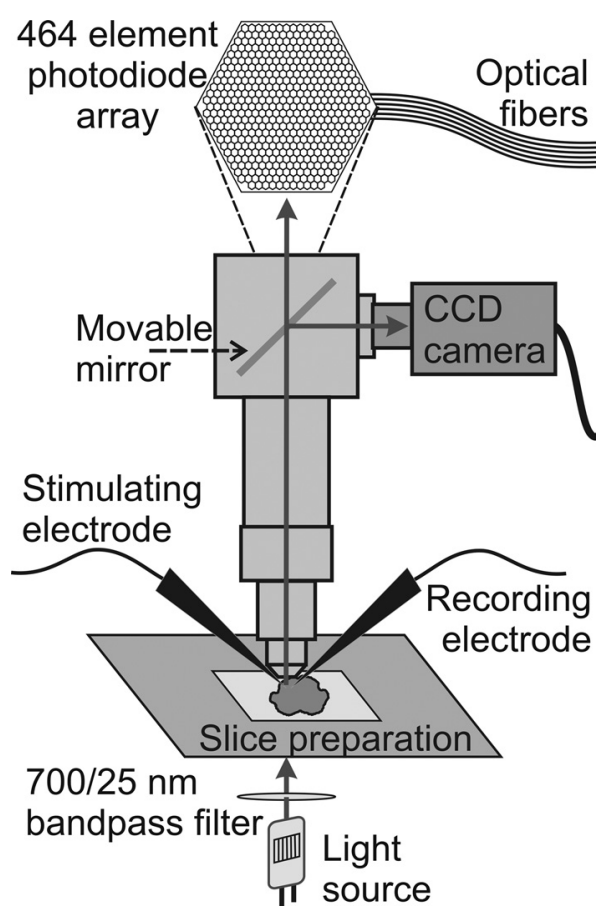

Figure 1. Experimental setup. Schematic diagram of the microscope, photodiode array, and slice preparation show the basic components of the setup used for imaging experiments. The stimulating and recording electrodes (local field potential recordings) are shown. Arrows indicate the direction of light.

were displayed as the change in transmitted light intensity divided by the resting light intensity $(\Delta \mathrm{I} / \mathrm{I})$. Noise in optical traces was reduced by a three-point binomial temporal filter and slow drift was corrected by fitting the baseline to a third-order polynomial. Spatial response maps with signal amplitude encoded as color were created from the maximum amplitude of each trace within a specified time window. Maps were smoothed by linear interpolation and by applying a Gaussian spatial filter with a space constant of half the inter-photodiode distance.

Distances from the stimulating electrode to each photodiode were calculated by first defining the axes parallel and perpendicular to the lamina at the site of stimulation as the "zero" axes. Traces along dorsoventral and mediolateral paths were selected with reference to these axes. Distances were calculated for each trace as the length of a straight line from zero to the center of the selected photodiode, assuming a regular hexagonal photodiode with a center-to-center distance of $67 \mu \mathrm{m}$. Due to curving of the SC laminae and the position of the slice under the photodiodes, the selected diodes were adjusted to straightened dorsoventral and mediolateral axes for plotting.

Data were exported to Matlab for further analysis (Mathworks). A Gaussian function of the form $F=A \times \exp \left[-(x-\mu)^{2} /\left(2 \times \sigma^{2}\right)\right]$, where $A$ is the maximum from baseline, $\mu$ is the mean, and $\sigma$ is the SD, was fitted to the data using the least-squares method. The fitted parameters were averaged over all slices. Additionally, three-dimensional mesh/surface plots in Cartesian space were created using linear interpolation between points for smoothing edges and bilinear interpolation of values at each vertex for smoothing face color. Statistics were performed in Matlab using the two-tailed Wilcoxon rank-sum test to assess whether independent samples were from identical, continuous distributions with equal medians. The significance level was set to 0.05 .

\section{Results}

Two-component voltage imaging responses in SC

Electrical stimulation of SC slices evoked highly characteristic optical responses that could be seen over much of the field of view. Membrane depolarization decreases light absorption by the voltage-sensitive dye $\mathrm{RH} 482$ and is reported here as a positive 

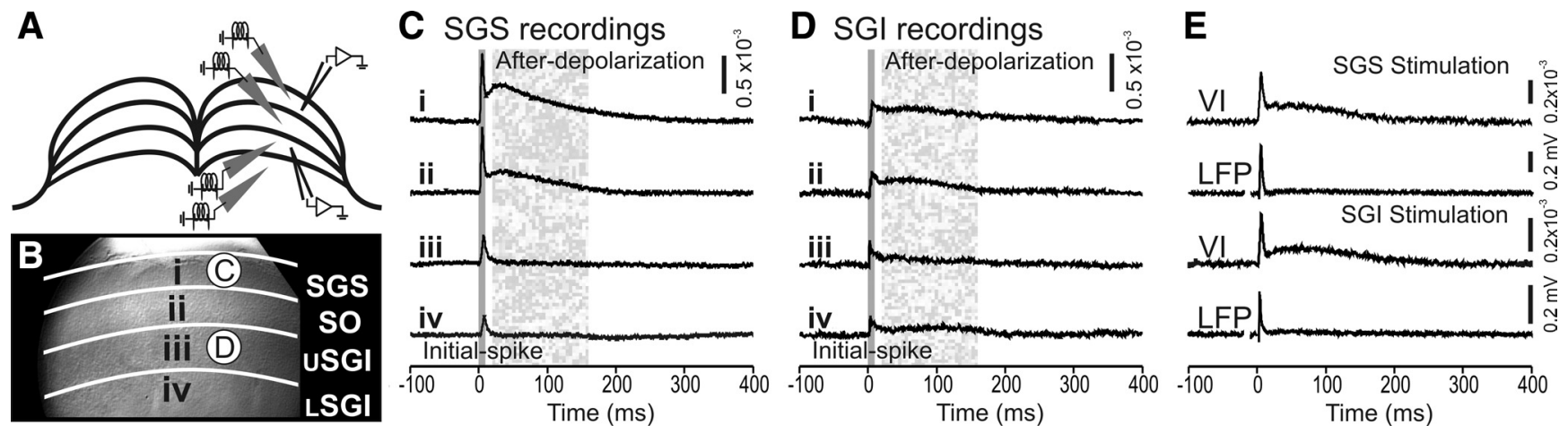

Figure 2. Electrical stimulation evoked two-component optical responses. $\boldsymbol{A}$, Schematic diagram of a coronal $\mathrm{SC}$ slice (cortex removed). Gray triangles show four sites of stimulation within $\mathrm{SC}$ laminae. Open triangles represent the sites from which voltage imaging traces were recorded and are displayed in $\boldsymbol{C}$ and $\boldsymbol{D}$. $\boldsymbol{B}, C \mathrm{CD}$ image of the SC diagramed in $\boldsymbol{A}$. $\boldsymbol{i}$-iv, Stimulation sites. The layers of the SC are labeled and demarked with white lines. $\mathrm{S} S \mathrm{GI}$, Upper SGI; $\mathrm{SGI}$, lower SGI. Circles labeled $\mathrm{C}$ and D indicate the sites from which voltage traces were recorded and are displayed in $\boldsymbol{C}$ and $\boldsymbol{D}$. C, Voltage imaging traces from the SGS (circle C in B) following stimulation at each of the four sites. Traces show 100 ms before and 400 ms following electrical stimulation (applied at time 0 ). Initialspike $(0-10 \mathrm{~ms})$ and after-depolarization $(20-160 \mathrm{~ms})$ components are shaded in gray. $\boldsymbol{D}$, Voltage imaging traces from the $S \mathrm{Gl}$ (circle $D$ in $\boldsymbol{B}$ ). Arrangement is the same as in $\boldsymbol{C}$. Scale bars, $\Delta \mathrm{I} / \mathrm{I}=$ $0.5 \times 10^{-3} . \boldsymbol{E}$, Comparison of voltage imaging $(\mathrm{VI})$ traces $(\Delta \mathrm{l} / \mathrm{I})$ and LFP recordings $(\mathrm{mV})$ from the SGS following both SGS stimulation and SGI stimulation. Scale bars: $\Delta \mathrm{I} / \mathrm{I}=0.2 \times 10^{-3}, 0.2 \mathrm{mV}$, respectively.

signal. These optical signals were seen within the layer of stimulation as well as in other layers of the SC. Each of these forms of spread is described in detail below. Figure $2, A$ and $B$, shows a sketch and a CCD image of a coronal slice through the rat SC. Stimulation was applied at four selected laminae, as follows: stratum griseum superficiale (SGS), stratum opticum (SO), upper stratum griseum intermediale (SGI), and lower SGI. Sites of stimulation and recording are marked in both panels. Optical responses observed in the SGS (Fig. 2C) and the SGI (Fig. 2D) are shown for stimulation applied within each of the four laminae.

Responses throughout the SC generally exhibited two temporal components regardless of the site of stimulation. The first component, referred to here as the initial-spike, appeared $\sim 2 \mathrm{~ms}$ after stimulation and peaked within $10 \mathrm{~ms}$ (Fig. 2C,D, solid shading). After the initial-spike decreased, the second component began. This second component, referred to as the afterdepolarization, peaked within $30-50 \mathrm{~ms}$ and decayed slowly to end $\sim 200-300 \mathrm{~ms}$ after stimulation (Fig. 2C,D, stippled shading). The initial-spike was also visible in local field potential recordings (LFPs), regardless of whether stimulation was applied to the SGS or SGI (Fig. 2E). By contrast, the after-depolarization was less prominent in LFPs than in optical signals recorded from the same location. This is likely because optical signals using voltage-sensitive dyes measure changes in membrane potential whereas LFPs measure extracellular fields generated by local membrane currents. This difference in the after-depolarization measured by LFPs and voltage imaging indicates that the slow voltage changes of the after-depolarizations are generated by much smaller membrane currents than those responsible for the initial-spike. Voltage imaging studies of the optic tectum of fish (SC homolog in lower vertebrates) have led to a similar conclusion (Kinoshita et al., 2002).

Two-component optical signals have also been reported in hippocampal slices, where the slow component, which resembles the after-depolarization in SC described here, was shown to reflect glutamate transporter currents in glial cells (Kojima et al., 1999). To test whether our signals arose from neurons, we applied DL-threo- $\beta$-hydroxyaspartic acid, a glutamate transporter inhibitor (Kojima et al., 1999). Blockade of glial glutamate transporters resulted in no change in the initial-spike or after- depolarization ( $N=5 ; p=0.13$ and 0.68 , respectively) (data not shown), thus indicating a neuronal origin for both components.

Essentially, all electrically evoked optical signals in SC slices displayed both an initial-spike and an after-depolarization. However, the relative amplitudes of these components as well as their temporal and spatial patterns of spread varied considerably, depending on the layer in which they were recorded and the layer to which stimulation was applied. A comparison of Figure $2 C$ and Figure $2 D$ shows that both components are strongest in the SGS when stimulation was applied to the SGS (Fig. 2Ci). The amplitudes of both components decreased in the SGS as the stimulation site shifted ventrally (Fig. 2Ci-iv). In the SGI, the initial-spike and after-depolarization were much smaller, regardless of the site of stimulation, and decreased little as the site of stimulation shifted dorsally (Fig. $2 \mathrm{Di}-i v$ ). Additionally, after-depolarizations showed higher slice-to-slice variability than did initial-spikes.

To assess the two components quantitatively, we defined the initial-spike as the maximum $\Delta \mathrm{I} / \mathrm{I}$ (change in light intensity relative to resting light intensity) from 0 to $10 \mathrm{~ms}$ after stimulation and the after-depolarization as maximum $\Delta \mathrm{I} / \mathrm{I}$ from 20 to $160 \mathrm{~ms}$ after stimulation. These time windows are highlighted in gray in Figure 2, $C$ and $D$. For the traces shown in Figure $2 C$, the amplitude of the initial-spike was $0.90 \times 10^{-3}$ in the SGS with SGS stimulation (Fig. 2Ci) and decreased to $0.24 \times 10^{-3}$ with stimulation in the lower SGI (Fig. 2Civ). Similarly, the amplitude of the after-depolarization was $0.50 \times 10^{-3}$ in the SGS with stimulation in the SGS (Fig. 2Ci) and decreased to $0.04 \times 10^{-3}$ with stimulation in the lower SGI (Fig. 2Civ). In the SGI (Fig. 2D), the amplitude of the initial-spike did not vary significantly, ranging from 0.14 to $0.15 \times 10^{-3}$ with stimulation in the SGS to lower SGI; the amplitude of the after-depolarization decreased slightly from $0.11 \times 10^{-3}$ to $0.09 \times 10^{-3}$ for these stimulation sites. Although these amplitudes are from a single example slice, similar trends were observed in virtually all slices tested (22 for SGS stimulation and 15 for SGI stimulation). These differences became important when we compared the spatial distributions of activity across the SC (see below).

The two components of these electrically evoked responses differed in their dependence on synaptic transmission, action potential conduction, and $\mathrm{GABA}_{\mathrm{A}}$ receptor-mediated inhibition. 
Before turning to the pharmacological experiments, we describe the spatial response patterns of activity across the SC following stimulation in different SC laminae.

\section{Spatial distribution of activity throughout the SC}

Since the activation of large populations of neurons within the SC is thought to underlie saccade generation (Lee et al., 1988; McIlwain, 1991), we examined patterns of population response using singlepulse stimulation. To evaluate this spread, we generated maps in which signal magnitude (normalized to the value at the site with greatest response) was encoded as color. Maps of the initial-spike (maximum $\Delta \mathrm{I} / \mathrm{I} \quad 0-10 \mathrm{~ms}$ after stimulation) showed intralaminar as well as interlaminar spread for both SGS and SGI stimulation (Fig. 3Aii,Bii). Maps of the after-depolarization (maximum $\Delta \mathrm{I} / \mathrm{I} 20$ $160 \mathrm{~ms}$ after stimulation) resembled initialspike maps, although the lower amplitude of the after-depolarization compared with the initial-spike made their spatial patterns more difficult to discriminate (Fig. 3Aiii,Biii). The response maps in Figure 3, Aii and Bii, show that stimulation in either the SGS or SGI evoked strong responses throughout the superficial SC, with the maximum intensity falling either in the SGS (Fig. 3Aii) or at the border between SGS and SO (Fig. 3Bii). Response amplitude decreased with mediolateral distance from the stimulating electrode. However, the extent of the mediolateral spread in the superficial layers differed depending on the site of stimulation. Stimulation in the SGS generally produced less extensive spread in the superficial layers compared with stimulation in the SGI (Fig. 3Aii,Bii).

We quantified the differences in mediolateral spread by plotting $\Delta \mathrm{I} / \mathrm{I}$ (averaged across experiments) versus distance. Since the plots were generally bell-shaped, we fitted Gaussian functions and used the full width at half maximum (FWHM) of the Gaussian as a quantitative index of spread (Fig. 4). For stimulation in the SGS, the initial-spike distribution within the SGS had a FWHM of $647 \pm 18 \mu \mathrm{m}$ (Fig. $4 A$, black points and line) and the after-depolarization distribution had a FWHM of $555 \pm 28 \mu \mathrm{m}$ (Fig. $4 B$, black points and line). For stimulation in the SGI, the initial-spike distribution within the SGS had a FWHM of $930 \pm$ $30 \mu \mathrm{m}$ (Fig. 4A, gray points and line) and the after-depolarization distribution had a FWHM of $1104 \pm 96 \mu \mathrm{m}$ (Fig. $4 B$, gray points and line). This indicates that SGI stimulation evoked SGS responses that extended almost twice the intralaminar distance of responses evoked by SGS stimulation. This difference was significant for both initial-spike and after-depolarization $(p<$ 0.0001 ).

In addition to the stimulation site-dependent differences in SGS mediolateral spread, there were differences in the extent of the two response components. Following SGS stimulation, the intralaminar spread of the initial-spike was significantly more extensive than that of the after-depolarization (FWHM, $647 \mu \mathrm{m}$ vs $555 \mu \mathrm{m} ; p<0.05$ ) (Fig. 4C). In contrast, following SGI stimulation, the after-depolarization spread significantly more than the initial-spike (FWHM, $1104 \mu \mathrm{m}$ vs $930 \mu \mathrm{m} ; p<0.05$ ) (Fig. $4 C$ ). This analysis provides a quantitative verification of the qualitative observations shown in Figure 3. The results indicate that stimulating the SGI activates SGS circuitry more effectively than stimulating the SGS directly.

The fact that stimulating the SGS elicited responses in the SGI, and vice versa, indicates that, in addition to the intralaminar spread described above, activity also spread between the layers, i.e., interlaminarly. The spread from SGS to the SGI is consistent with recent whole-cell patch-clamp reports (Lee et al., 1997; Isa et al., 1998). A novel observation reported here with voltage imaging was that SGI stimulation evoked strong responses in the SGS. This finding suggests the existence of an excitatory interlaminar pathway from the SGI to SGS.

\section{Temporal response patterns: intralaminar spread}

The spatial map representation just presented provides no information about the timing of responses in different locations. To analyze the dynamics of spread, we constructed three-dimensional plots, with amplitude encoded as color, position on the ordinate, and time on the abscissa. Selecting a mediolateral path within the SGS or SGI allowed us to track the spread of activity in that lamina over time (Fig. 5). Selecting a dorsoventral path allowed us to track the spread of activity between laminae over time (Fig. 6). The color along one horizontal line corresponds to an optical trace taken from a given location. Hotter colors indicate higher signal amplitudes as in Figure 3, except that here amplitude is measured over time ( $x$-axis) at a particular location. In contrast, the color in Figure 3 indicates the maximum amplitude during a particular time window throughout the entire field of view.

The three-dimensional plots in Figures 5 and 6 reveal the same two distinct temporal components evident in optical traces (Fig. 
A Initial-spike

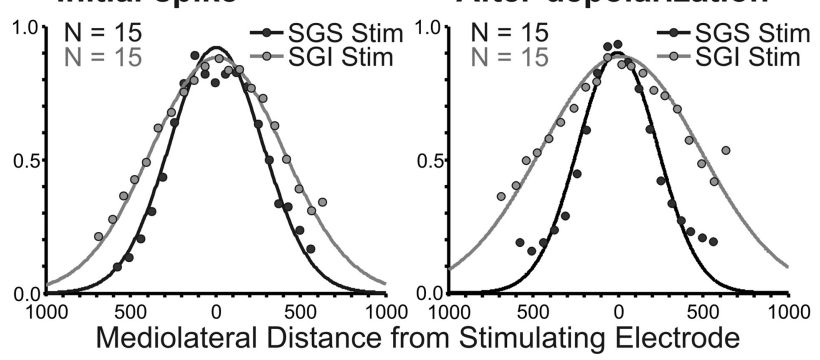

B After-depolarization

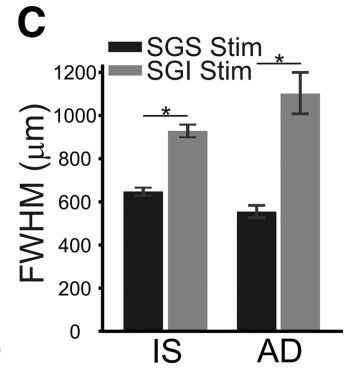

Figure 4. The highest amplitude mediolateral spread appears in SGS following stimulation (Stim) in either SGS or SGI. $\boldsymbol{A}$, Normalized signal amplitude $[(\Delta \mathrm{I} / \mathrm{I}) /$ maximum I] is plotted against mediolateral distance through the SGS from the site of the stimulation (zero distance) for the initial-spike $(0-10 \mathrm{~ms})$. Black points show the amplitude after SGS stimulation. Gray points show the amplitude following SGI stimulation. The curves are Gaussian functions that were fitted to the data points from each experiment $(N=15)$. $\boldsymbol{B}$, After-depolarization data $(20-160 \mathrm{~ms})$ arranged as in $\boldsymbol{A}$. $\boldsymbol{C}$, The mean and SE of the FWHM calculated from the fits for the slices is plotted for initial-spike (IS) and after-depolarization (AD) data. Black bars are data from SGS stimulation. Gray bars are data from SGI stimulation. $N=15 .{ }^{*} p<0.05$.

Superficial Layer Stimulation:

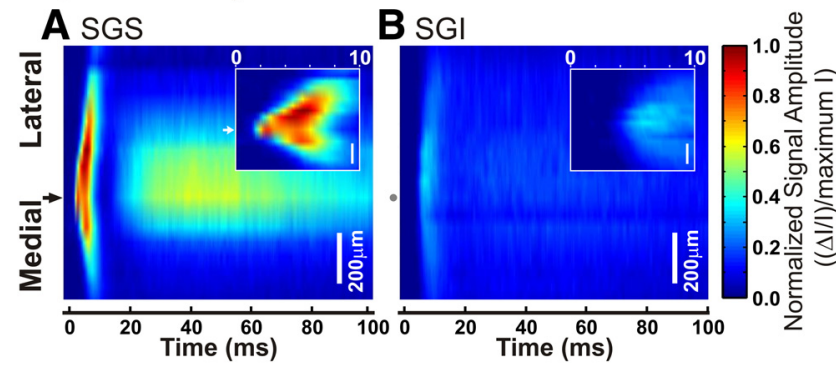

Intermediate Layer Stimulation:

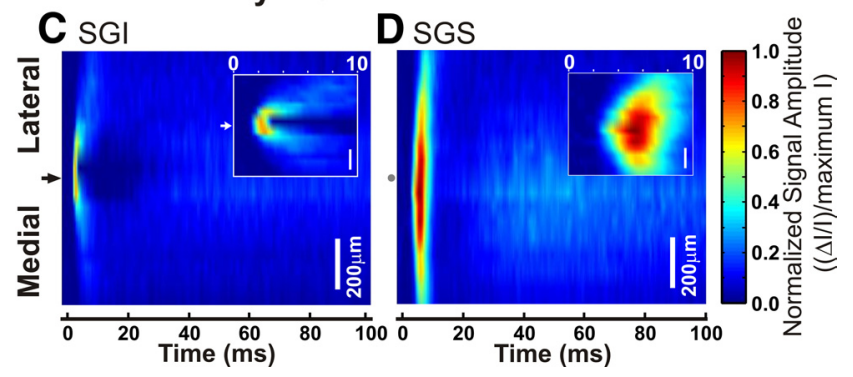

Figure 5. A single pulse of electrical stimulation evokes a response that spreads widely throughout the layers of the SC. $\boldsymbol{A}-\boldsymbol{D}$. Three-dimensional color maps show the electrically induced signal amplitude within each lamina over time. Mediolateral distance from the stimulation site is on the $y$-axis, with black arrows on the left to show the points of stimulation. Gray dots correspond to the stimulation site in the opposite lamina. Scale bars, $200 \mu \mathrm{m}$. Time is shown on the $x$-axis from 0 to $100 \mathrm{~ms}$ after stimulation. Signal intensity is normalized to the maximum intensity of all diodes throughout the slice. Hotter colors indicate higher signal amplitude. Insets, Expanded view of $0-10 \mathrm{~ms}$ after the onset of the stimulation. $\boldsymbol{A}$, Spread of activity in SGS after SGS stimulation. $B$, Spread of activity in SGI after SGS stimulation. C, Spread of activity in SGI after SGI stimulation. D, Spread of activity in SGS after SGI stimulation.

$2 C-E)$. The insets in Figure 5 expand the view of the initial-spike. The initial-spike and after-depolarization were especially clear in the plot of interlaminar spread through the SGS following SGS stimulation (Fig. 5A). In the example shown, the initial-spike first appeared at the site of stimulation (Fig. $5 \mathrm{~A}$, black arrow) and then spread $\sim 350 \mu \mathrm{m}$ medially and $\sim 500 \mu \mathrm{m}$ laterally with similar velocities. Note that since activation within a layer takes a few milliseconds, dependence on synaptic events is suggested (see below). Since signals were normalized to the peak response throughout all layers, and because responses in the SGS were much greater than responses in the SGI following SGS stimulation, SGI signals appear to be relatively weak (Fig. $5 B$ ). Nevertheless, the light blue regions in Figure $5 B$, as well as individual traces recorded in the SGI (Fig. 2Di), indicate that following SGS stimulation, the initial-spike and afterdepolarization spread into the intermediate SC.

Stimulation in the SGI initiated a different spatiotemporal pattern of spread, especially around the site of stimulation. Signals within the SGI were localized around the stimulating electrode and did not propagate more than $\sim 250 \mu$ m medially or laterally (Fig. $5 C$ ). This contrasts sharply with what we observed after SGS stimulation (Fig. 5A). Furthermore, within a few milliseconds of stimulation in SGI, there was an initial depolarizing response followed by a marked decrease in signal at the site of stimulation (Fig. $5 C$, inset). We did not see a similar region of local inhibition after stimulation of the SGS, although areas of highest signal intensity in this example were lateral to the site of stimulation (Fig. $5 \mathrm{~A}$, inset). Additionally, initial-spikes evoked by SGI stimulation spread into the SGS and then spread mediolaterally within the SGS (Fig. 5D). Interestingly, responses within the SGS following SGI stimulation spread at least $150 \mu \mathrm{m}$ farther than responses following SGS stimulation, with the spread extending beyond the $1 \mathrm{~mm}$ field of view (Figs. 4, 5A,D). As seen in Figure 2, $C$ and $D$, the afterdepolarization was small following stimulation of the SGI and after normalization to the maximum intensity it was hardly visible (Fig. $5 B, C$ ).

\section{Temporal response patterns: interlaminar spread}

To visualize the temporal patterns of interlaminar spread, we generated three-dimensional plots with vertical paths along a dorsoventral axis from the SGS, through the SO and SGI, and into deeper layers of the SC (Fig. 6). Again, the two temporal components were clearest in the SGS following SGS stimulation. The initial-spike first appeared at the site of stimulation and traveled $\sim 650 \mu \mathrm{m}$ downward into the deeper layers (Fig. $6 \mathrm{~A}$, red and light blue). Figure $6 B$ shows an expanded time frame of the initialspike to emphasize the temporal aspects of ventrally directed propagation. The after-depolarization peaked $\sim 40 \mathrm{~ms}$ after stimulation and had the highest amplitude within the superficial layers (Fig. 6A, light blue). Due to the normalization used for display in Figure $6 A$, the high intensity signals within the superficial layers obscured the signals in the deep layers. We therefore renormalized the color scale to exclude the greater amplitude signals in superficial layers (Fig. 6A, inset). The optical signals from the upper and lower SGI remained above baseline for at least $80 \mathrm{~ms}$ following stimulation of the SGS. This indicates that both the initial-spike and after-depolarization spread ventrally into the SGI. Additionally, representative traces illustrate the amplitudes of the two components from each SC lamina and provide clear evidence for a pathway from SGS to SGI (Fig. 6C).

Responses evoked by stimulation in the SGI spread $\sim 450 \mu \mathrm{m}$ dorsally, showing the highest level of activity in the SGS and SO, even though the stimulation was applied ventrally to these sites, in the SGI (Fig. 6D). Note that although the graphs for SGS and SGI stimulation were normalized independently, the maximum intensity following SGI stimulation lies slightly ventral when 


\section{Superficial Layer Stimulation:}
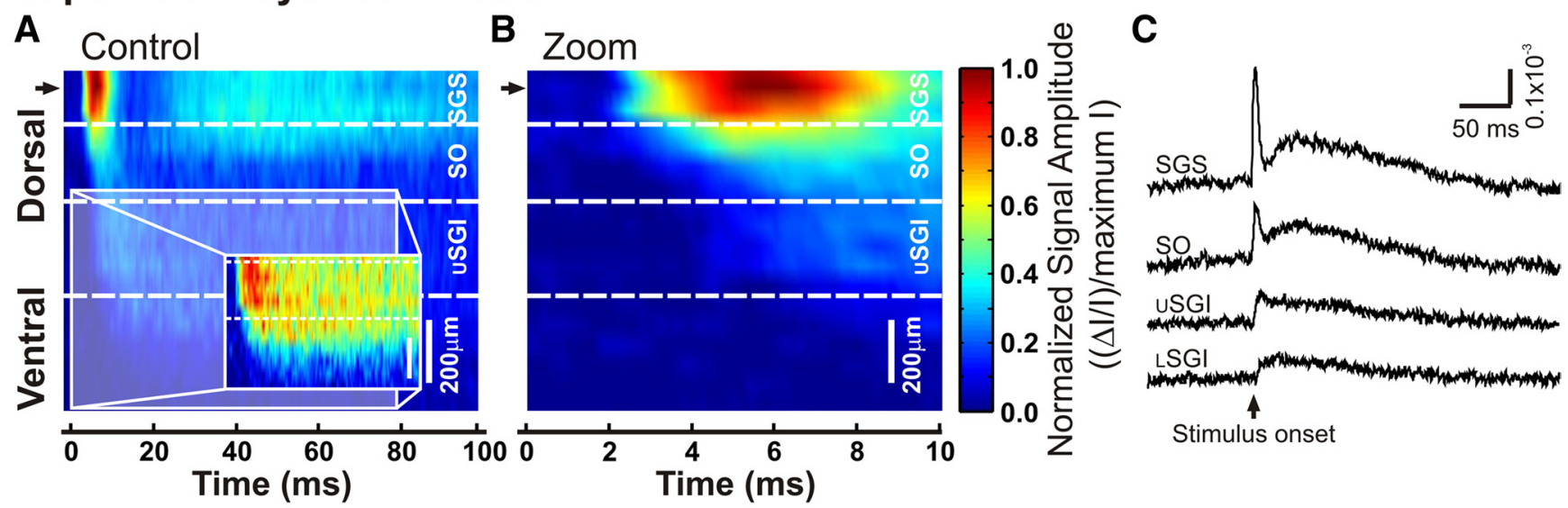

\section{Intermediate Layer Stimulation:}
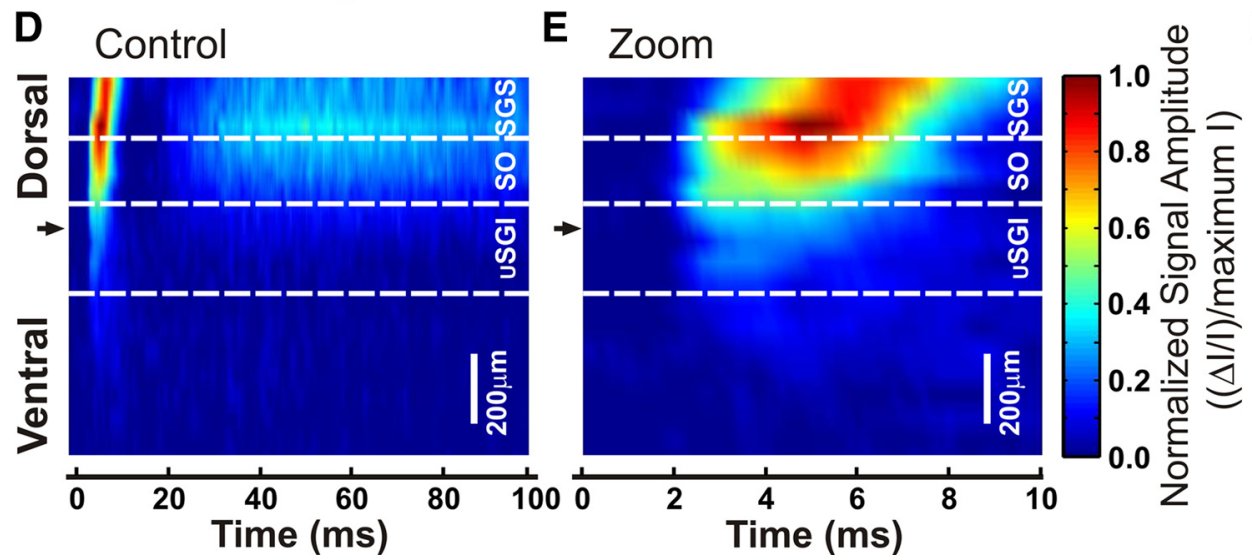

$\mathbf{F}$

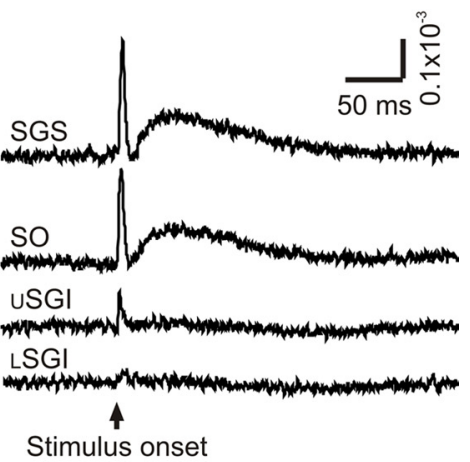

Figure 6. A single pulse of stimulation evokes a response that spreads widely between the layers of the $S C . A, B, D, E$, Three-dimensional color maps show the time course of response spread following electrical stimulation. The dorsoventral location along a selected path in the $S C$ is shown on the $y$-axis. Black arrows show the sites of stimulation. Scale bars, $200 \mu \mathrm{m}$. Time is shown on the $x$-axis from 0 to $100 \mathrm{~ms}$ after stimulation. Signal intensity is normalized to the maximum of all diodes on the selected path. Hotter colors indicate higher signal amplitude. Dotted white lines

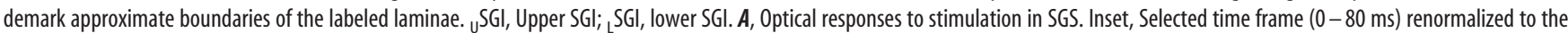
maximum intensity within the selected dorsoventral region to show the spread of activity into the $S G I$. $\boldsymbol{B}$, An expanded view of $\boldsymbol{A}$, showing $0-10 \mathrm{~ms}$. $\boldsymbol{C}$, Representative traces selected from each lamina along the dorsoventral path. The upward arrow indicates the time of stimulation and the responses are shown as $\Delta \mathrm{I} / \mathrm{I}$. $\boldsymbol{D}$, Three-dimensional color map as in $\boldsymbol{A}$ for $S G \mid$ stimulation. $\boldsymbol{E}$, $\boldsymbol{F}$, Same as $\boldsymbol{B}$ and $\boldsymbol{C}$, respectively, for $S G I$ stimulation.

compared with SGS stimulation. This point will be discussed further below. Figure $6 E$ shows a temporally expanded view of the initial-spike that accentuates the dorsally directed propagation from the site of stimulation in the SGI to the SGS over $\sim 5$ $\mathrm{ms}$. This timing is consistent with a role for synaptic transmission. Further evidence for a dorsally directed excitatory pathway appears in the optical traces from different layers of the SC, which show that the initial-spike and after-depolarization were largest in the superficial layers of the SC (Fig. 6F).

Spatiotemporal analysis: velocity

Optical signals clearly spread within and between layers, so we explored the mechanisms underlying this spread. To evaluate the average speed of initial-spikes in various directions, we plotted latency (time to reach maximum amplitude) versus distance from the site of stimulation (Fig. 7). A rapid, linear increase in latency would suggest action-potential conduction. Latency plots are shown only for the initial-spike because the slow time course of the after-depolarization precluded the analysis of its propagation. Lines were fit to the plots of each slice and conduction velocity was calculated from the slope. Points closest to and farthest away from the site of stimulation were omitted from the fits for accuracy. Velocity is reported as the average from these individual plots over all slices (Table 1). With stimulation in the SGS, the response latency near the stimulating electrode was $\sim 2-4 \mathrm{~ms}$, reflecting the time it takes for the stimulation to initiate a response and for this response to reach its peak (Fig. 7Ai). This plot shows that optical signals spread $600 \mu \mathrm{m}$ in $\sim 6 \mathrm{~ms}$ with approximately equal propagation velocities of $\sim 0.1 \mathrm{~m} / \mathrm{s}$ both medially and laterally (Table 1). This velocity is consistent with conduction in fine, unmyelinated axons in the posterior pituitary (Zhang et al., 2007). However, conduction velocity within the SC has received little attention (Liu and Luo, 1996).

The initial-spike evoked by SGS stimulation appeared in the SGI at $\sim 6 \mathrm{~ms}, \sim 3 \mathrm{~ms}$ after it first appeared in the SGS (Fig. $7 A i, A i i)$. Fitting lines yielded velocities of $\sim 0.1 \mathrm{~m} / \mathrm{s}$ for this layer as well (Table 1). To explore the signal propagation from SGS to SGI further, we plotted the time for initial-spikes to travel interlaminarly from the site of stimulation in the SGS into the SGI. The time to traverse this pathway was $\sim 3-4 \mathrm{~ms}$, with a velocity of $\sim 0.1 \mathrm{~m} / \mathrm{s}$ (Fig. 7Aiii, Table 1). These latencies are consistent with the synaptic pathway into the SGI previously identified with whole-cell patch-clamp methods (Hall and Lee, 1993, 1997; Lee et al., 1997; Isa et al., 1998, 2002; Isa and Hall, 2009). 
A SGS Stimulation

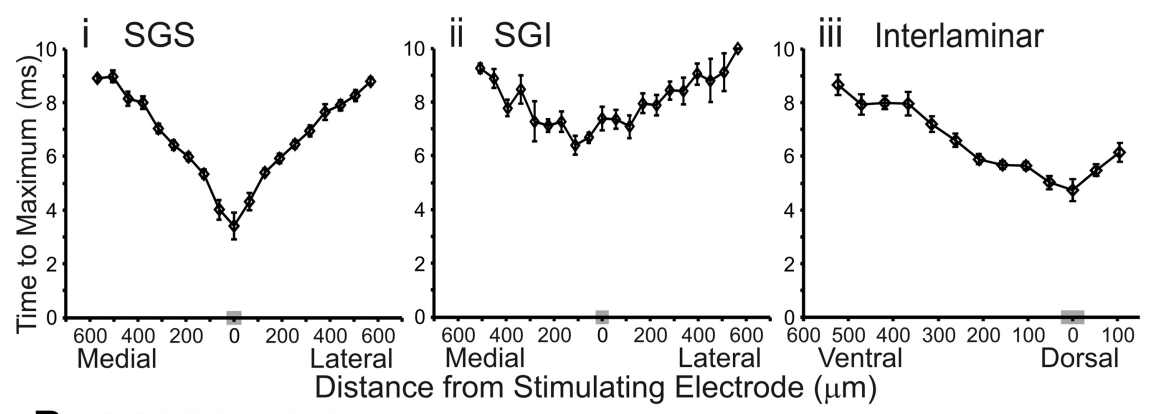

B SGI Stimulation

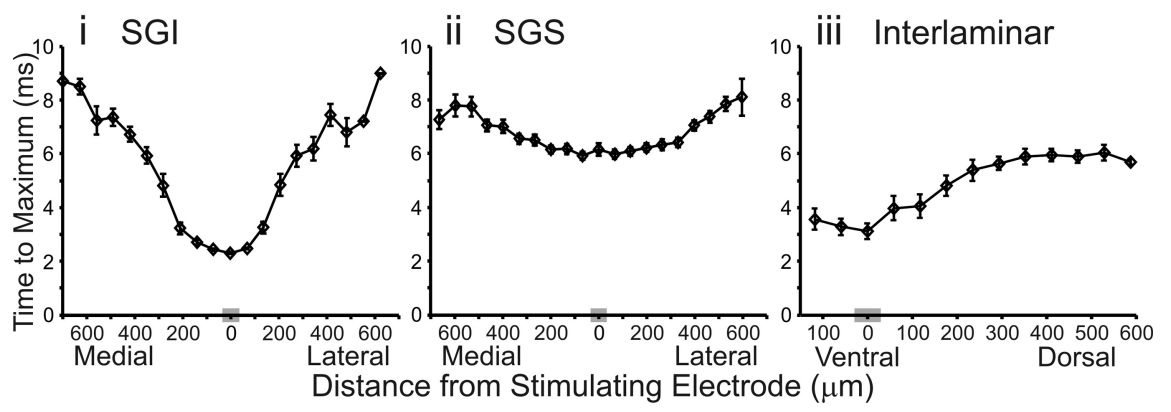

Figure 7. Plots of latency versus distance. $\boldsymbol{A}, \boldsymbol{B}$, Time to maximum response amplitude is plotted against the mediolateral or dorsoventral distance from the stimulation site. Mediolateral diodes are binned (based on distance) into 20 discrete points and dorsoventral data are binned into 13 discrete points, with each point representing the mean of diodes within that bin. The gray box on the $x$-axis is the bin containing diodes closest to the axis of stimulation (zero distance). The vertical lines through the points indicate SE. $\boldsymbol{A}$, Latency plots following SGS stimulation $(N=15)$. $\boldsymbol{i}$, Mediolateral plot of SGS responses. $\boldsymbol{i i}$, Mediolateral plot of SGI responses. iii, Dorsoventral plot. $\boldsymbol{B}$, Latency plots following SGI stimulation $(N=15)$. $\boldsymbol{i}$, Mediolateral plot of SGI responses. ii, Mediolateral plot of SGS responses. iii, Dorsoventral plot.

We examined latency plots for SGI stimulation and found interesting differences between the circuitry activated compared with SGS stimulation. Upon stimulation of the SGI, the initialspike was evident within $\sim 3 \mathrm{~ms}$, again representing the time it took for the stimulation to activate the neuronal elements and for signals to peak (Fig. 7Bi). Fitting lines yielded an estimate of the mean conduction velocity of SGI responses to SGI stimulation of $\sim 0.08 \mathrm{~m} / \mathrm{s}$ (Table 1 ), which is only slightly slower than in the SGS (Fig. 7Ai). In the SGS, the initial-spike evoked by SGI stimulation appeared $\sim 4-5 \mathrm{~ms}$ after it appeared in the SGI (Fig. 7Bi,Bii). Once appearing in the SGS, the initial-spike spread with a velocity approximately twice that seen following SGS stimulation $(\sim 0.2$ $\mathrm{m} / \mathrm{s}$ ) (Table 1). We next examined the interlaminar spread of activity from SGI to SGS. In this case, the initial-spike appeared $\sim 3 \mathrm{~ms}$ after stimulation in SGI and traveled into the SGS with a velocity of $\sim 0.1 \mathrm{~m} / \mathrm{s}$ (Fig. 7 Biii).

The spatiotemporal pattern of signal spread can also be visualized with a sequence of color-coded maps at regular intervals. A sequence at $0.4 \mathrm{~ms}$ intervals from 1 to $7 \mathrm{~ms}$ after stimulation showed the initial-spike reaching its peak and then beginning to decrease (Fig. 8). The response to SGS stimulation initially spread in an almost radial pattern, with the excited region growing larger in each frame. The intralaminar spread within the SGS only slightly outpaced the interlaminar spread into the SO and SGI (Fig. $8 \mathrm{~A}$, supplemental Video 1, available at www.jneurosci.org as supplemental material). The regions of highest signal intensity lay within the superficial layers at locations medial and lateral to the point of stimulation. This may represent increased local inhibition at the stimulating electrode. Nevertheless, the response at the site of SGS stimulation shows less local inhibition than that seen following SGI stimulation (Figs. 5, 8). In fact, SGI stimula- tion produced a strikingly different response pattern throughout the SC. The signal started at the point of stimulation and spread dorsally at first, but when excitation reached the SO and SGS ( $\sim 3 \mathrm{~ms})$, where $\Delta \mathrm{I} / \mathrm{I}$ was greatest, the spread altered course. Signals began to propagate intralaminarly within the SGS (Fig. $8 B$, supplemental Video 2, available at www. jneurosci.org as supplemental material). This second phase of spread followed a lateral trajectory as excitation filled the SO and SGS, but was largely excluded from the SGI. At the site of stimulation in SGI, we saw radial spread of local inhibition starting at $\sim 2.6 \mathrm{~ms}$ and continuing past $7.0 \mathrm{~ms}$ (Fig. $8 \mathrm{~B}$ ). This likely represents an activation of inhibitory circuitry and is much stronger than, if not distinctly different from, that seen in the SGS. These distinct patterns of signal propagation indicate that stimulation in the different layers activates different elements of SC circuitry.

\section{The role of synapses and action potentials}

To evaluate the contributions of major synaptic receptor types to voltage-sensitive dye signals, we tested the action of AMPA receptor antagonist NBQX $(5 \mu \mathrm{M})$ and NMDA receptor antagonist APV (50 $\mu \mathrm{M})$. We also evaluated the role of action-potential conduction by applying TTX (300 nM) to block voltage-gated $\mathrm{Na}^{+}$channels. All drugs were applied by changing the perfusing solution after establishing a stable baseline of responses to electrical stimulation $(100 \mu \mathrm{A}, 200 \mu \mathrm{s})$. Figure 9, $A-C$, shows example control responses and responses after successive changes to NBQX and NBQX + TTX for SGS stimulation; the time courses of druginduced changes in initial-spike and after-depolarization amplitudes are shown in the inset.

NBQX reduced the amplitude of both response components, but generally had greater effects on initial-spikes. For example, with stimulation and recording in the SGS, NBQX significantly reduced the initial-spike by $42 \%$ and the after-depolarization by $38 \%(p<0.01)$ (Fig. 9A,B,D, black bars). SGS stimulation evoked somewhat smaller responses in the SGI, but NBQX significantly reduced the initial-spikes and after-depolarizations by 53 and 29\%, respectively ( $p<0.01$ ) (Fig. 9D, dark gray bars). Following SGI stimulation, NBQX significantly reduced the initialspike in the SGS by 71\% $(p<0.01)$, but the small reduction of the after-depolarization in the SGS of $12 \%$ was not significant $(p=$ 0.13 ) (Fig. 9D, medium gray bars). With SGI stimulation, NBQX reduced initial-spikes and after-depolarizations in the SGI only slightly and these changes were not statistically significant ( $p=$ 0.68 and 0.13 , respectively) (Fig. $9 D$, light gray bars). These results indicate that SGS stimulation strongly activates AMPA receptors throughout the SGS and SGI, and that SGI stimulation activates AMPA receptors strongly in the SGS, but weakly in the SGI. These results, together with the timing analyses discussed above, illustrate the considerable influence of AMPA receptor-mediated synaptic transmission on population responses in the SC. 
Table 1. Axonal propagation velocity

\begin{tabular}{|c|c|c|c|c|c|}
\hline & \multicolumn{2}{|c|}{ Intralaminar SGS } & \multicolumn{2}{|c|}{ Intralaminar SGI } & \multirow[b]{2}{*}{ Interlaminar } \\
\hline & Lateral & Medial & Lateral & Medial & \\
\hline \multicolumn{6}{|c|}{ SGS stimulation } \\
\hline Velocity & $110.6 \pm 10.0$ & $106.7 \pm 6.1$ & $110.7 \pm 11.7$ & $99.2 \pm 13.0$ & $111.4 \pm 14.3$ \\
\hline$R^{2}$ & $0.95 \pm 0.01$ & $0.96 \pm 0.01$ & $0.90 \pm 0.03$ & $0.89 \pm 0.02$ & $0.91 \pm 0.02$ \\
\hline \multicolumn{6}{|c|}{ SGI stimulation } \\
\hline Velocity & $240.7 \pm 15.3$ & $259.6 \pm 31.6$ & $72.2 \pm 5.0$ & $79.7 \pm 8.2$ & $141.1 \pm 21.1$ \\
\hline$R^{2}$ & $0.86 \pm 0.02$ & $0.85 \pm 0.04$ & $0.93 \pm 0.01$ & $0.95 \pm 0.01$ & $0.87 \pm 0.02$ \\
\hline
\end{tabular}

Average velocity of initial-spike propagation was calculated by fitting lines to the maximum latency data of each slice, plotted as distance traveled versus time. The reciprocal of the slope for the fitted line equals the conduction velocity in $\mu \mathrm{m} / \mathrm{ms} \pm$ SE. Intralaminar plots were divided into lateral and medial directions so that lines could be fitted in each direction.

\section{A SGS Stimulation}

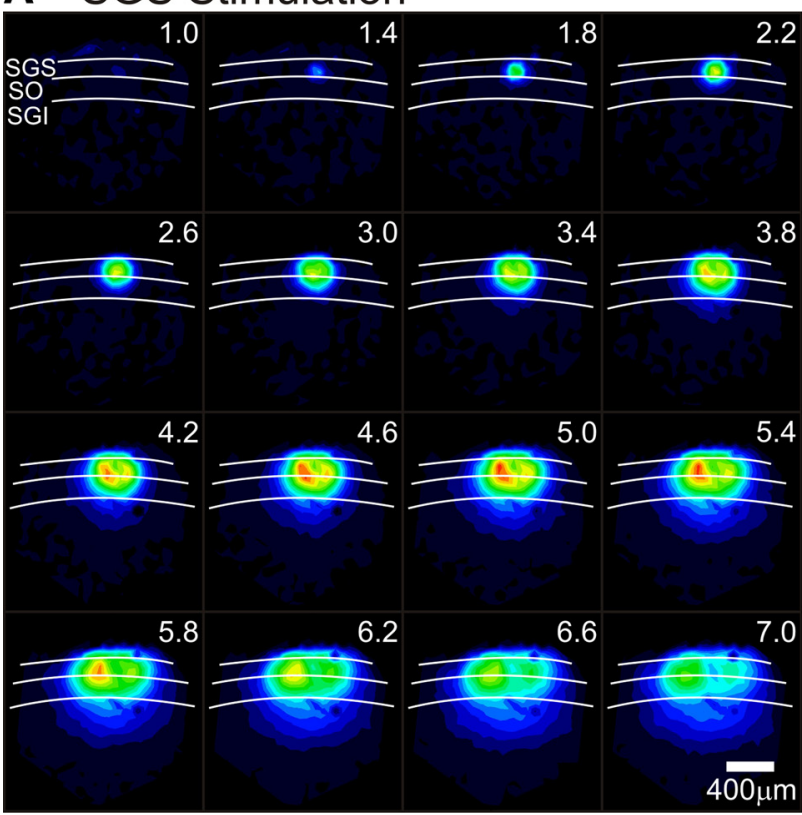

\section{B SGI Stimulation}

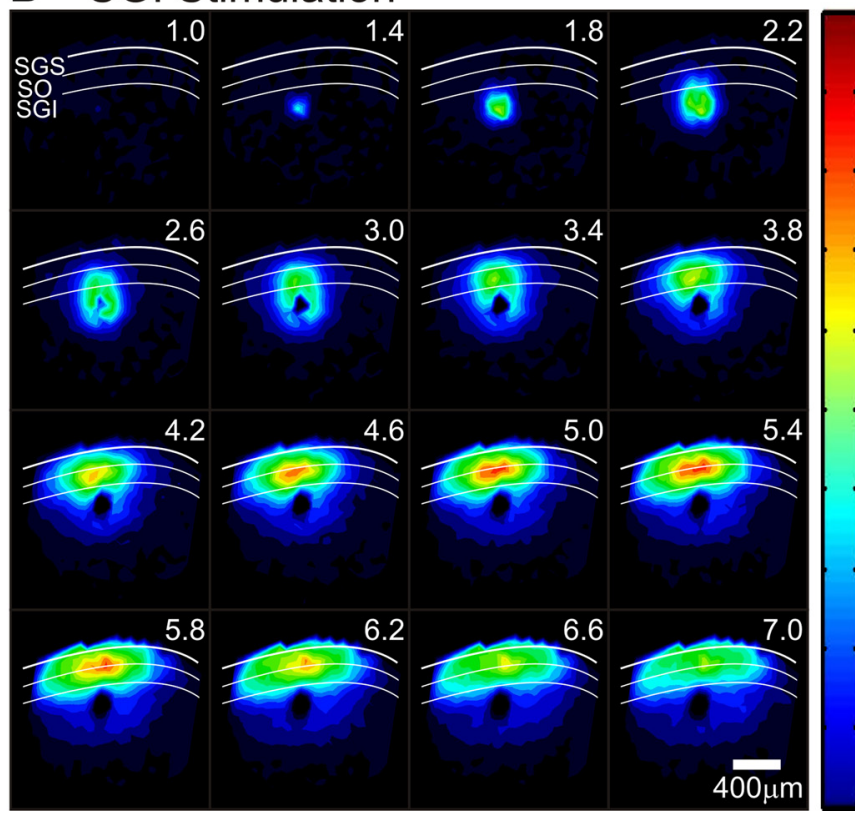

Figure 8. $\quad \boldsymbol{A}, \boldsymbol{B}$, Serial images $1-7 \mathrm{~ms}$ after electrical stimulation (every $0.4 \mathrm{~ms}$ ). White curves denote the layers of the $S C$ and layers are labeled in the first record (1 ms after stimulation). All records are normalized to the same maximum and signal amplitude is encoded as color, with hotter colors indicating higher amplitude signals. The color scale is shown on the right. Scale bars, $400 \mu \mathrm{m}$. $\boldsymbol{A}$, Time course of optical responses after stimulation of the SGS. $\boldsymbol{B}$, Time course of optical responses after stimulation of the SGI.

Applying TTX (in the continued presence of NBQX) blocked both the remaining initial-spike and the remaining afterdepolarization. With SGS responses to SGS stimulation, TTX significantly reduced the initial-spike by $86 \%$ and the afterdepolarization by $57 \%(p<0.01)$ (Fig. $9 E$, black bars). In the SGI, the initial-spike evoked by stimulation in the SGS significantly decreased by $56 \%$ and the after-depolarization decreased by $25 \%(p<0.01)$ (Fig. $9 E$, dark gray bars). Responses evoked by SGI stimulation in the presence of NBQX were also significantly reduced by TTX, with initial-spikes in the SGS falling $84 \%$ and after-depolarizations falling 64\% $(p<0.01)$ (Fig. $9 E$, medium gray bars). The large NBQX-resistant responses in the SGI following SGI stimulation fell 89\% (initial-spikes) and 53\% (afterdepolarizations) $(p<0.01)$ (Fig. 9E, light gray bars). Since TTX effectively blocked the initial-spikes and after-depolarizations throughout the SC, we conclude that residual responses seen after NBQX addition depend predominantly on voltage-gated $\mathrm{Na}^{+}$ channels.

To see how pharmacological manipulations influenced the overall patterns of activity in the SC, we examined spatial maps of initial-spike amplitude before and after drug application. These maps show how NBQX reduced the spread of responses evoked by stimulation in either SGS (Fig. $10 B, C$ ) or SGI (Fig. 10F, G). The reduction is especially clear for the areas of highest response amplitude that extend through the SGS and SO. Consistent with synaptic activation throughout the laminae, NBQX greatly reduced the extent of both mediolateral and dorsoventral spread following SGS stimulation. Moreover, NBQX almost completely blocked the mediolateral spread that follows dorsoventral spread of initial-spikes into the SGS following SGI stimulation. Quantitative analyses of drug effects on mediolateral and dorsoventral spread are described in greater detail below. Block by NBQX is a further indication that the high amplitude signals in the superficial layers are likely synaptically driven. These maps also show that the blockade by TTX was evident throughout the slice. The only remaining optical responses following TTX application were small residual signals within $\sim 50 \mu \mathrm{m}$ of the site of stimulation (Fig. 10D,H). Residual responses reflected direct depolarization of the cell membrane by the stimulating electrode. These spatial response maps confirm that responses throughout the SC are activated by AMPA receptors and $\mathrm{Na}^{+}$channel-dependent action potentials. These results confirm that orthodromic activation is likely the major contributor to our optical signals.

\section{The role of $\mathrm{GABA}_{\mathrm{A}}$ receptor mediated inhibition on} optical signals

Since electrical activity in the SC is regulated by GABA (Chevalier et al., 1985; Chevalier and Deniau, 1990; Hall and Lee, 1993; Lee 


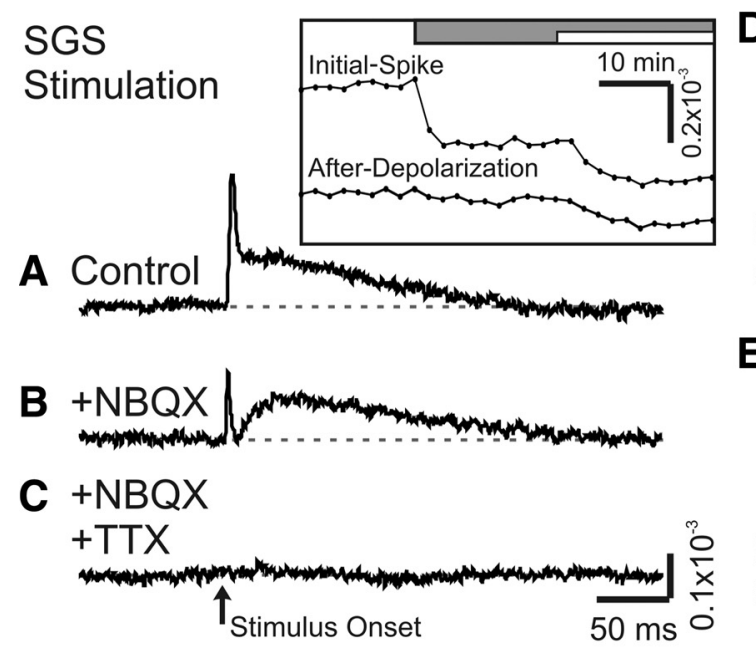

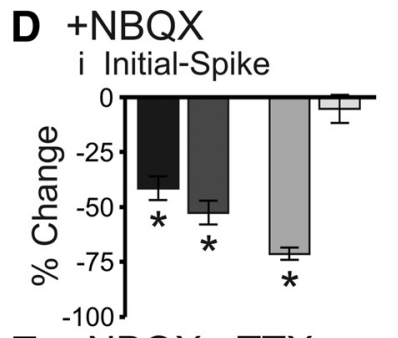

E + NBQX + TTX

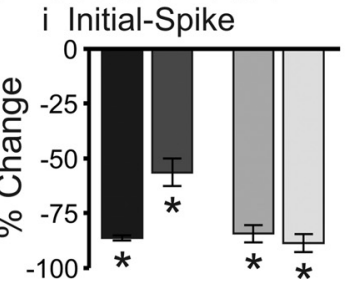

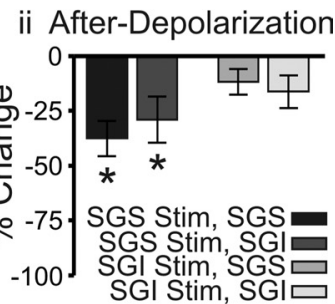

ii After-Depolarization

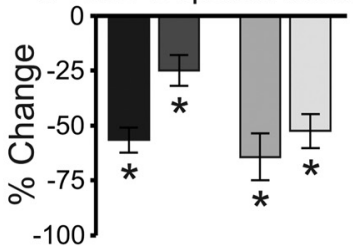

Figure 9. NBQX and TTX block optical signals evoked by SC stimulation. $A$, Control trace from a single photodiode within the SGS following SGS stimulation $(N=1)$. The inset shows the time course of drug application for the two components, the initial-spike and the after-depolarization. The gray bar indicates the time of the addition of $5 \mu \mathrm{m}$ NBQX to the bath solution. The white bar indicates the time of addition of $5 \mu \mathrm{M}$ NBQX plus $300 \mathrm{~nm}$ TTX to the bath solution. $\boldsymbol{B}$, Optical signal as in $\boldsymbol{A}$ after addition of NBQX $(N=1)$. C, Optical signal as in $\boldsymbol{A}$, after addition of NBQX plus TTX (N $=1$ ). The arrow indicates the time of stimulation. Di, Percentage change of the initial-spike component $(0-10 \mathrm{~ms})$ from control following addition of NBQX $(N=5)$. Shades of gray indicate stimulation (Stim) site and recording layer. Vertical lines through the bars indicate SE. ${ }^{*} p<0.05$. Dii, Percentage change of the after-depolarization component ( $\left.20-160 \mathrm{~ms}\right)$ from control following addition of NBQX $(N=5)$. $\boldsymbol{E}$, Same as in $\boldsymbol{D}$, after bath application of NBQX and TTX $(N=5)$.
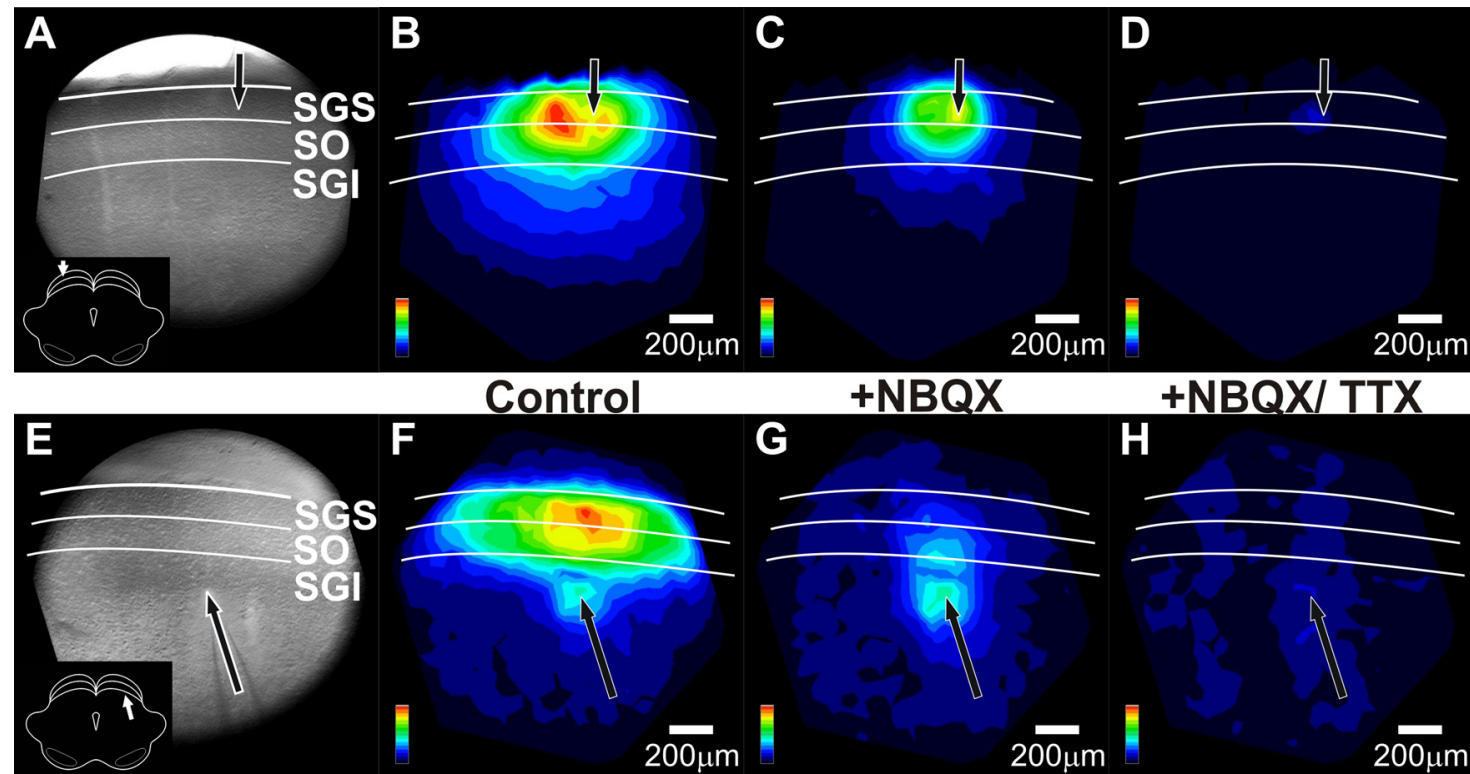

+ NBQX
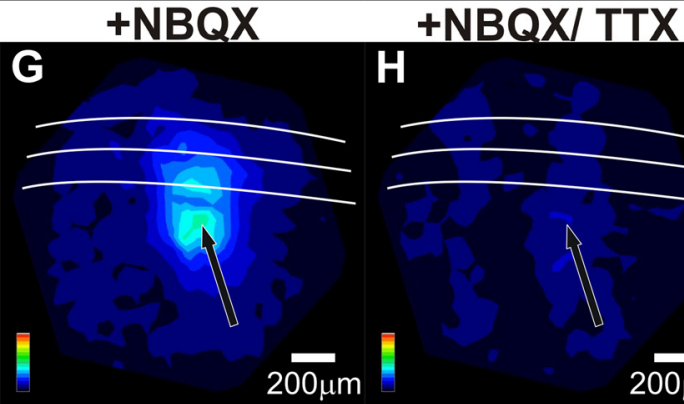

H

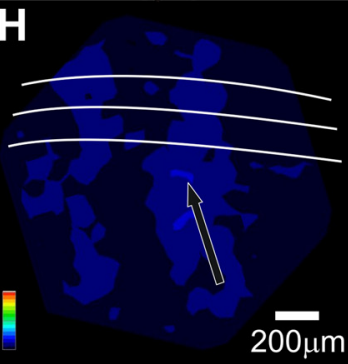

Figure 10. NBQX and TTX alter the spatial patterns of initial-spikes in SC. $A, C C D$ image of the $S C$ slice preparation. The arrow indicates the point of stimulation and the inset shows orientation of the coronal slice (cortex removed). White lines and labels denote the layers of the SC. B, Color map image of the initial-spike signal propagation following SGS stimulation before drug application, normalized to the maximum amplitude of the initial-spike $(0-10 \mathrm{~ms})$. Hotter colors indicate higher amplitude signals. Color scales are in the lower right corner of each panel. Layers of the $\mathrm{SC}$ are

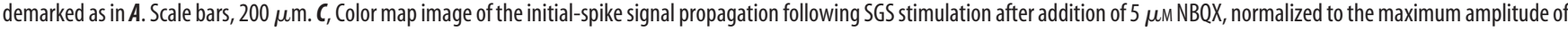
the initial-spike before drug application, i.e., the data shown in B. D, Color map image of the initial-spike signal propagation following SGS stimulation after addition of $5 \mu \mathrm{m} \mathrm{NBQX} \mathrm{plus} 300 \mathrm{~nm}$ TTX. The normalization is the same as in $\boldsymbol{B}$ and $\boldsymbol{C}$. $\boldsymbol{E}-\boldsymbol{H}$, Same as $\boldsymbol{A}-\boldsymbol{D}$, respectively, but for $S G I$ stimulation. Note that cortex is not removed in the CCD image in $\boldsymbol{E}$.

et al., 2001, 2007; Behan et al., 2002; Kaneda et al., 2008; Isa and Hall, 2009), we tested the actions of two $\mathrm{GABA}_{\mathrm{A}}$ receptor antagonists, bicuculline $(50 \mu \mathrm{M})$ and gabazine (SR95531, $5 \mu \mathrm{M})$ (bicuculline and gabazine were used interchangeably and the results combined). These drugs generally increased the amplitude of optical signals, but had the greatest effects on after-depolarizations (Fig. 11A,B). With stimulation in the SGS, the initial-spike and after-depolarization in the SGS significantly increased by 10 and $164 \%$, respectively $(p<0.05)$ (Fig. $11 D$, black bars). In the SGI, the initial-spike evoked by SGS stimulation increased by $8 \%$ ( $p=$
$0.18)$ and the after-depolarization increased by $116 \%(p<$ 0.001 ) (Fig. $11 D$, dark gray bars). Thus, within the SGI, only the increase in the after-depolarization was statistically significant. Responses to SGI stimulation showed similar trends; both components in the SGS and SGI generally increased following $\mathrm{GABA}_{\mathrm{A}}$ receptor blockade, but the effect on the after-depolarization was much greater. The initial-spike and after-depolarization in SGS significantly increased 19 and $184 \%$, respectively $(p<0.05)$ (Fig. $11 D$, medium gray bars), and the initial-spike and afterdepolarization in the SGI significantly increased by 11 and 76\%, 

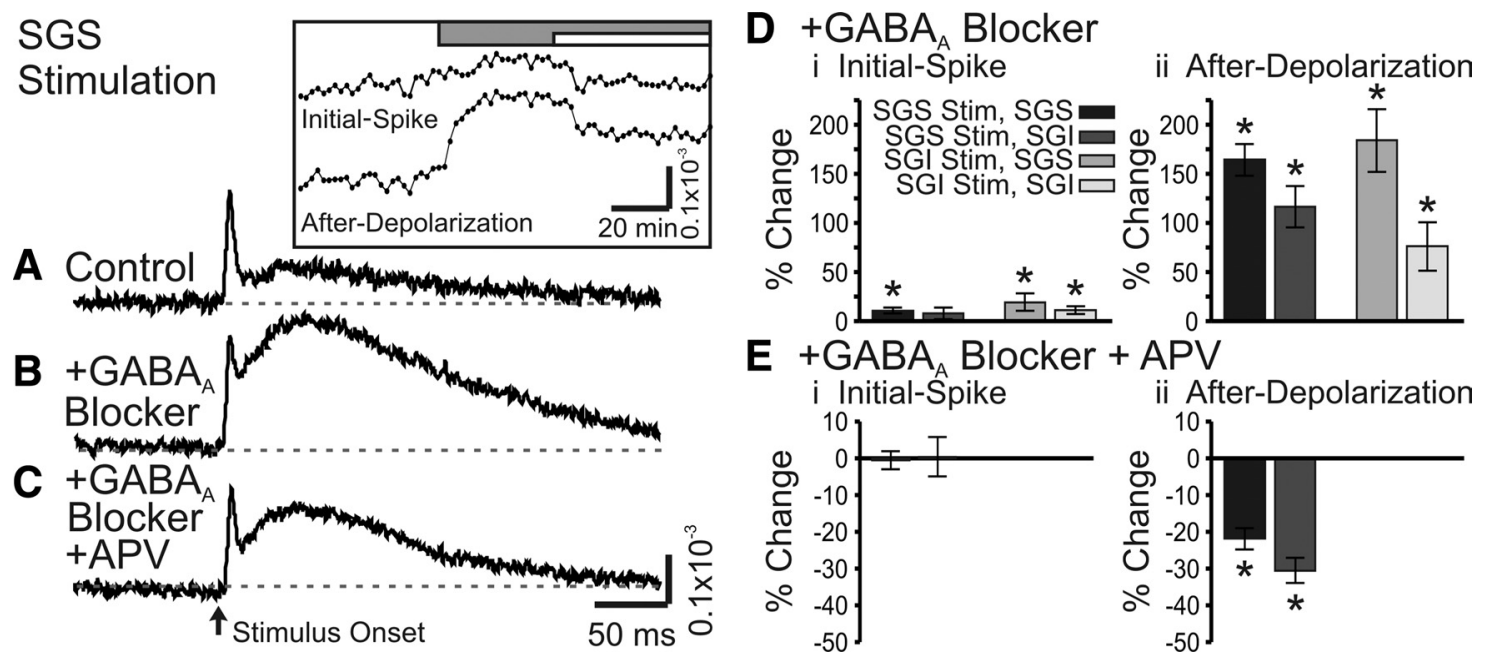

Figure 11. $G A B A_{A}$ receptor blockers enhance optical signals in SC. $A$, Control trace from a single photodiode within the SGS following SGS stimulation ( $N=1$ ). Inset, Time course of drug application for the two components, the initial-spike and the after-depolarization. The gray bar indicates the time of addition of $50 \mu \mathrm{m} G A B A_{A}$ receptor blocker (SR-95531). The white bar indicates the time of addition of $50 \mu \mathrm{M} G A B A_{A}$ receptor blocker plus $50 \mu \mathrm{m}$ APV. $\boldsymbol{B}, 0$ ptical signal as in $\boldsymbol{A}$ after addition of GABA $A_{A}$ receptor blocker (SR-95531) ( $N=1$ ). $\boldsymbol{C}, 0$ ptical signal as in $\boldsymbol{A}$ after addition of $G_{A B A_{A}}$ receptor blocker plus APV $(N=1)$. The arrow indicates the time of stimulation. Di, Percentage change of the initial-spike component $(0-10$ ms) from control following bath application of $\mathrm{GABA}_{\mathrm{A}}$ receptor blocker (bicuculline or SR-95531, $N=7$ ). Shades of gray indicate stimulation (Stim) site and recording layer. Vertical lines through the bars indicate $S E$. ${ }^{*} P<0.05 . \mathrm{Dii}$, Percentage change of the after-depolarization component (20-160 ms) from control following bath application of $G A B A_{A}$ receptor blocker $(N=7)$. $E$, Same as in $\boldsymbol{D}$, after addition of $G A B A_{A}$ receptor blocker and APV (SGS stimulation only).

respectively $(p<0.05)$ (Fig. $11 D$, light gray bars). These results indicate a strong inhibitory influence of $\mathrm{GABA}_{\mathrm{A}}$ receptors on $\mathrm{SC}$, with specific emphasis on longer latency signals.

Addition of APV in the presence of $\mathrm{GABA}_{\mathrm{A}}$ receptor antagonists significantly reduced the amplitude of the after-depolarization evoked by stimulation in SGS, with decreases of $22 \%$ in SGS and $31 \%$ in SGI $(p<0.001)$ (Fig. 11C,Eii). However, the initial-spike in both locations remained relatively unchanged. Note that APV application was only performed on SGS stimulation trials. Despite the reductions, the after-depolarizations remained greater than control responses recorded before $\mathrm{GABA}_{\mathrm{A}}$ receptor blockade. In fact, we found that APV had little if any effect on control responses before $\mathrm{GABA}_{\mathrm{A}}$ receptor blockade (data not shown). Based on these results, we conclude that $\mathrm{GABA}_{\mathrm{A}}$ receptors serve as important modulators of activity within the SGS and SGI. Furthermore, $\mathrm{GABA}_{\mathrm{A}}$ receptor activation limits the spread of activity between the SGS and SGI, consistent with whole-cell patch-clamp studies (Saito and Isa, 2003). These results indicate that, under control conditions with functional inhibitory synapses, AMPA receptors make the predominant contribution to the excitatory spread of the afterdepolarization. However, when $\mathrm{GABA}_{\mathrm{A}}$ receptors are blocked, both AMPA and NMDA receptors contribute to the spread of the after-depolarization.

Spatial maps further illustrate how $\mathrm{GABA}_{\mathrm{A}}$ receptor blockade altered the spread of after-depolarizations throughout the SC. With stimulation in the SGS, GABA receptor blockade greatly enhanced the spread of after-depolarizations through the SGS and SO (Fig. 12 B,C). Note that in Figure 12, the spatial maps were normalized to the maximum after-depolarization following $\mathrm{GABA}_{\mathrm{A}}$ receptor blockade (Fig. $12 C, G$ ). Taking this into account, the spread of the control after-depolarization in Figure $12 B$ is comparable to that in Figure 3Aiii. Figure 12, $F$ and $G$, shows similar patterns as Figure 12, $B$ and $C$, for the after-depolarizations evoked by SGI stimulation. $\mathrm{GABA}_{\mathrm{A}}$ receptor blockade also increased the intralaminar spread of signals (Fig. 12C,G). The faint blue regions in the SGI and deep layers (Fig. 12C,G) indicate that $\mathrm{GABA}_{\mathrm{A}}$ receptors ordinarily limit the spread of ac- tivity into this region, consistent with recent reports (Saito and Isa, 2003; Phongphanphanee et al., 2008; Isa and Hall, 2009). Quantitative analyses of drug effects on mediolateral and dorsoventral spread are described in detail below (Figs. 13, 14). Supplemental Figure 1 (available at www.jneurosci.org as supplemental material) shows a three-dimensional plot of interlaminar spread that confirms the increase in signal amplitude and spread after addition of $\mathrm{GABA}_{\mathrm{A}}$ receptor blockers for both sites of stimulation. With both SGS and SGI stimulation, $\mathrm{GABA}_{\mathrm{A}}$ receptor blockade increased the amplitude of the after-depolarization throughout the SC.

To quantify how drug responses varied with mediolateral distance, we plotted response amplitude versus position along horizontal paths within the SGS and SGI. Figure 13, $A-D$, shows distributions of initial-spike amplitude through the SGS and SGI following stimulation in each layer, for control responses, responses in NBQX, NBQX + TTX, GABA receptor antagonists, and $\mathrm{GABA}_{\mathrm{A}}$ receptor antagonists $+\mathrm{APV}$. For ease of comparison, fold changes in amplitude are presented as bar graphs below the distributions to show the average response amplitude from traces along the selected paths $( \pm 400 \mu \mathrm{m}$ from stimulating electrode). Before drug application, SGS stimulation elicited initialspikes that spread $\sim 500 \mu \mathrm{m}$ medially and laterally (Fig. 13Ai, black line). NBQX reduced the initial-spike elicited by stimulation in the SGS, with the greatest reduction at distances of $\sim 200$ $400 \mu \mathrm{m}$ (Fig. 13Ai, black and red lines). The block by NBQX at these distances indicates that medial and lateral spread depend on synaptic transmission. These plots also confirm the nearly complete block of initial-spikes throughout the SGS by TTX (Fig. $13 A i$, blue line). Mediolateral plots through the SGI following SGS stimulation show slightly different patterns. Initial-spikes still spread $\sim 500 \mu \mathrm{m}$ medially and laterally before drug application, but NBQX blocked initial-spikes throughout the layer and TTX further blocked these signals (Fig. 13Bi, black, red and blue lines). The decreases in amplitude were statistically significant for the actions of NBQX and TTX on initial-spikes in SGS and SGI 

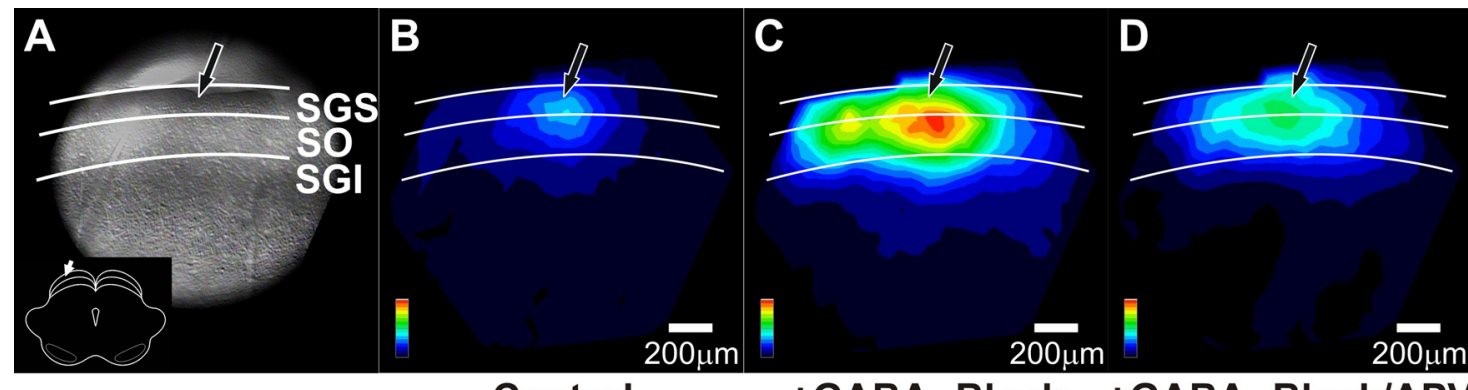

Control + GABA $_{A}$ Block + GABA $_{A}$ Block/APV

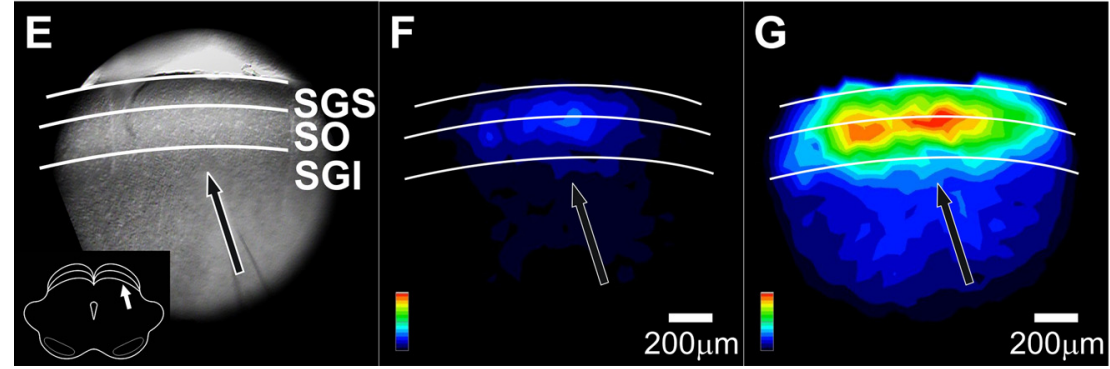

Figure 12. $G_{A B A_{A}}$ receptor blockers alter the spatial patterns of after-depolarizations in SC. $A, C C D$ image of the $S C$ slice preparation. The arrow indicates the point of stimulation and the inset shows orientation of the coronal slice (cortex removed). White lines and labels denote the layers of the SC. B, Color map image of the after-depolarization signal propagation following SGS stimulation before drug application, normalized to the maximum amplitude of the increased after-depolarization following $G_{A B A}$ receptor block. Hotter colors indicate higher amplitude signals. Color scales are in the lower right corner of each panel. Layers of the SC are demarked as in $\boldsymbol{A}$. Scale bars, $200 \mu m$. $\boldsymbol{C}$, Color map image of the after-depolarization signal propagation following SGS stimulation after addition of $50 \mu \mathrm{M} \mathrm{GABA}_{\mathrm{A}}$ receptor blocker, normalized to the maximum amplitude of after-depolarization following $\mathrm{GABA}_{\mathrm{A}}$ receptor block. $\boldsymbol{D}$, Color map image of the afterdepolarization signal propagation following SGS stimulation after addition of $50 \mu \mathrm{M} \mathrm{GABA}_{\mathrm{A}}$ receptor blocker plus $50 \mu \mathrm{m} A \mathrm{APV}$, normalized to the maximum amplitude of the after-depolarization following $\mathrm{GABA}_{\mathrm{A}}$ receptor block. $\boldsymbol{E}-\boldsymbol{G}$, Same as $\boldsymbol{A}-\boldsymbol{C}$, respectively, following $S \mathrm{GI}$ stimulation.

after stimulation in SGS $(p<0.01)$ (Fig. 13Aii,Bii, black, red and blue bars).

Initial-spikes within the SGI evoked by SGI stimulation spread $\sim 300 \mu \mathrm{m}$ medially and laterally and were not significantly reduced by NBQX ( $p=0.68$ ) (Fig. 13Dii, black and red bars). However, the initial-spikes were significantly reduced by TTX $(p<0.01)$ (Fig. 13Dii, red and blue bars). These results indicate that there is little to no synaptic propagation in the layer of stimulation. However, NBQX produced significant decreases of initial-spikes that spread $>1 \mathrm{~mm}$ throughout the SGS (Figs. 4, $13 \mathrm{Ci}$, black and red lines). This is another indication that interlaminar signals were mainly orthodromically activated and dependent on synaptic transmission. TTX reduced the remaining signals to baseline in both layers. Both decreases in amplitude were statistically significant for the initial-spikes in the SGS following SGI stimulation $(p<0.01)$ (Fig. 13Cii, black, red and blue bars). In general, these plots show that the spread of initialspikes depended on the activation of AMPA receptors and that residual responses seen after NBQX addition are action potentials that depend on voltage-gated $\mathrm{Na}^{+}$channels.

For all four initial-spike plots, $\mathrm{GABA}_{\mathrm{A}}$ receptor blockade increased signal throughout the SGS or SGI, with the greatest increase occurring at the axis of stimulation. The increases in initial-spikes seen in SGS with SGS stimulation, as well as in both SGS and SGI with SGI stimulation, were statistically significant $(p<0.05)$ (Fig. 13Aiii,Ciii,Diii, black and green bars). Only in the SGI after SGS stimulation did this drug effect fail to reach statistical significance $(p=0.18)$ (Fig. 13Biii, black and green bars). Addition of APV had no significant effect on the initialspike within the SGS or SGI following SGS stimulation ( $p=1.00$ for both) (Fig. 13Aiii,Biii, green and magenta bars). The plots show that $\mathrm{GABA}_{\mathrm{A}}$ receptors limit the amplitude and spread of the initial-spike and that NMDA receptors do not contribute to the initial-spike.
Plots of after-depolarization amplitude versus mediolateral position are shown in Figure 13E-H. These plots generally show weak block by NBQX and strong block by TTX over broad mediolateral regions of the SC slices. Note that the lowest afterdepolarization amplitudes in these plots reflect the noise level of the optical traces, so for the small after-depolarizations such as those in the SGI, signals appear incompletely blocked by TTX because of noise. However, individual traces show that TTX addition reduced responses to baseline (Fig. 9A-C). Before drug addition, after-depolarizations in the SGS evoked by SGS stimulation spread $\sim 350 \mu \mathrm{m}$ medially and laterally (Fig. 13Ei, black line). Both NBQX and TTX produced statistically significant reductions in the after-depolarization $(p<0.01)$ (Fig. 13Eii, black, red and blue bars). It is interesting to note that in the SGS following SGS stimulation, NBQX reduced $\Delta \mathrm{I} / \mathrm{I}$ to the greatest extent within $\sim 200 \mu \mathrm{m}$ of the site of stimulation. This contrasts with the action of NBQX on the initial-spike for the same layer and stimulation site, where the greatest block occurred between $\sim 200-$ $400 \mu \mathrm{m}$ from the stimulation site (Fig. 13Ai). Moreover, the after-depolarizations throughout the SGI following SGS stimulation spread $\sim 400-500 \mu \mathrm{m}$ medially and laterally before drug application (Fig. 13Fi, black line). These after-depolarizations were reduced significantly by NBQX but not by TTX $(p<0.01$ and 0.22 , respectively) (Fig. 13Fii, black, red, and blue bars). In the SGS and SGI following SGI stimulation, where control afterdepolarizations spread $\sim 400-500 \mu \mathrm{m}$ medially and laterally, NBQX did not significantly decrease the after-depolarizations ( $p=0.13$ for both) (Fig. 13Gii,Hii, black and red bars) but TTX $\operatorname{did}(p<0.01)$ (Fig. 13Gii,Hii, red and blue bars).

$\mathrm{GABA}_{\mathrm{A}}$ receptor blockade generally enhanced the afterdepolarization amplitudes by appoximately twofold; all the increases were significant $(p<0.05)$ (Fig. 13Eiii-Hiii, black and green bars). The subsequent addition of APV reduced these signals to an intermediate level between control and $\mathrm{GABA}_{\mathrm{A}}$ recep- 


\section{Superficial Layer Stimulation:}
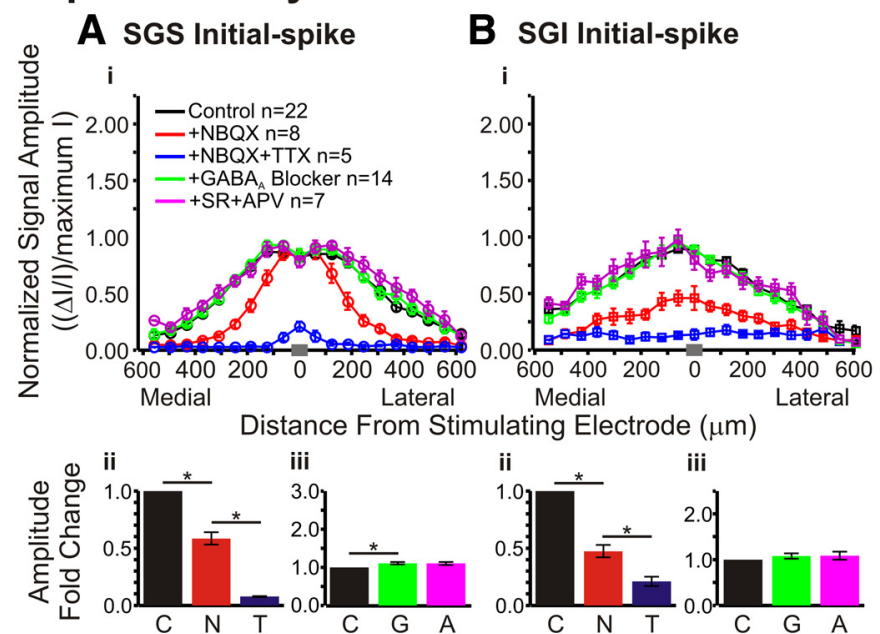

E sGS After-depolarization
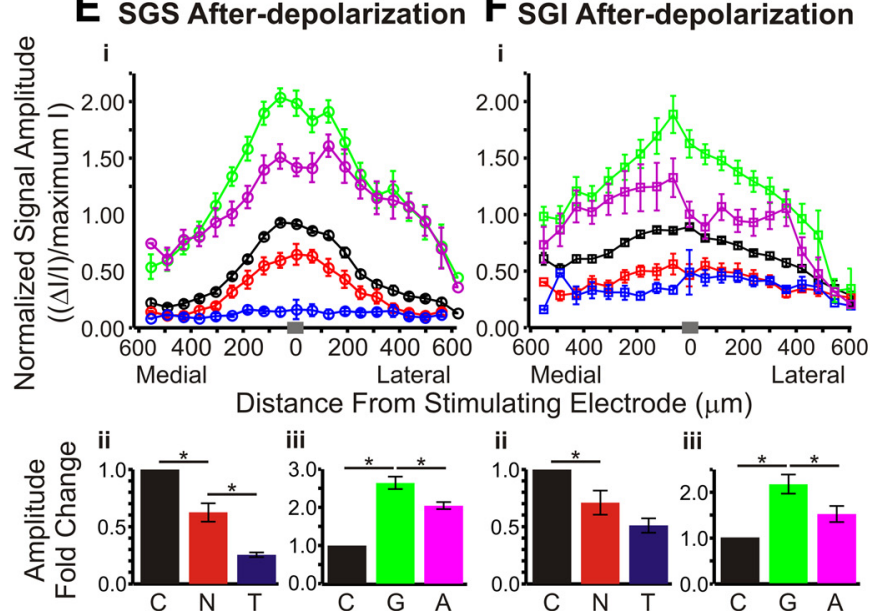

\section{Intermediate Layer Stimulation:}
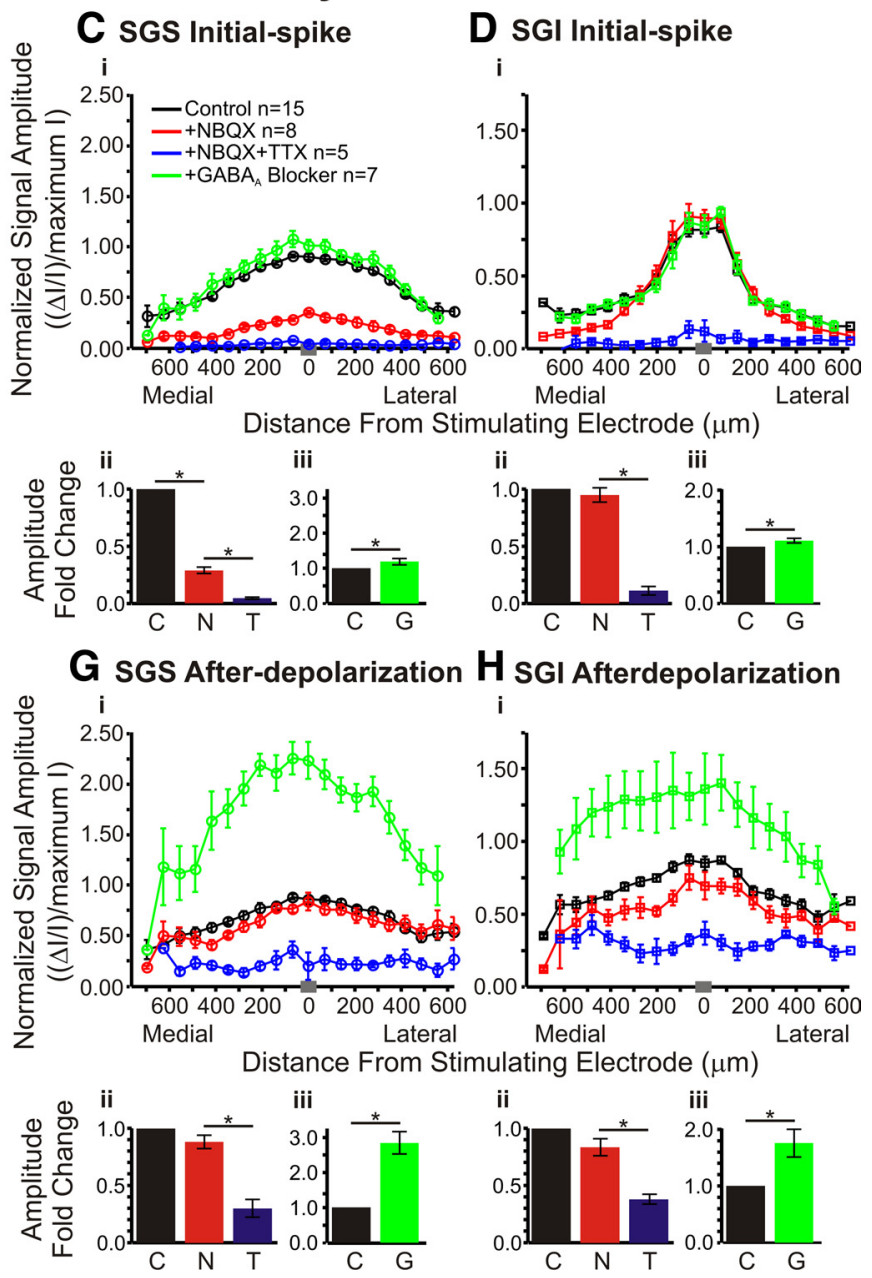

Figure 13. Pharmacological influences on the mediolateral distribution of responses within the SC. Normalized signal amplitude is plotted against distance from the stimulating electrode. The data were normalized to the maximum amplitude of the control (predrug) signal. Data are plotted before drug application (black; SGS stim: $N=22 ; S G I$ stim: $N=15$ ), after application of NBQX (red; SGS stimulus, $N=8 ; S G I$ stimulus, $N=8$ ), after application of NBQX and TTX (blue; $S G S$ stimulus, $N=5 ; S G$ stimulus, $N=5$ ), after application of GABA receptor blocker (green; $S G S$ stimulus, $N=$ $14 ; S G I$ stimulus, $N=7$ ), and after application of $G_{A B A}$ receptor blocker $(S R)$ and $A P V$ (magenta; $S G S$ stimulus, $N=7$ ). For all the plots, data were binned to provide 20 location points. The gray bar in each panel on the $x$-axis indicates the bin in which the zero distance occurred. Ai, Initial-spike (0-10 ms) data within the SGS following SGS stimulation. Aii, Aiii, Bar graphs plotting the fold changes in signal amplitude across slices. Data for bar graphs come from all diodes within $\pm 400 \mu \mathrm{m}$ the stimulating electrode. Vertical lines represent $S E$. ${ }^{*} p<0.05$. $C$, Control, no drug (black); $N$,

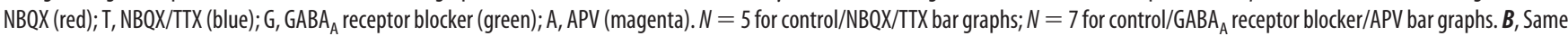
as in $\boldsymbol{A}$ for the initial-spike in the SGI following SGS stimulation. $\boldsymbol{C}$, Same as in $\boldsymbol{A}$ for the initial-spike in the SGS after SGI stimulation. Note that APV was not added in SGI stimulation experiments. $\boldsymbol{D}$, Same as in $\boldsymbol{C}$ for the initial-spikes within the SGI following SGI stimulation. $\boldsymbol{E}-\boldsymbol{H}$, Same as in $\boldsymbol{A}-\boldsymbol{D}$ for the after-depolarization (20-160 ms).

tor blockade (Fig. 13Ei,Fi, green and magenta lines). However, the decrease in signal was mainly observed within $\sim 300-400 \mu \mathrm{m}$ of the stimulating electrode. Beyond that column, APV had little effect. The APV-induced decreases in responses in the presence of $\mathrm{GABA}_{\mathrm{A}}$ receptor antagonists were statistically significant $(p<$ 0.05) (Fig. 13Eiii,Fiii, green and magenta bars). Note that APV was tested only for SGS stimulation experiments. Based on these results, we conclude that $\mathrm{GABA}_{\mathrm{A}}$ receptor blockade enhances both the initial-spike and after-depolarization throughout SC slices, but shows the greatest effect on the afterdepolarizations, especially those close to the axis of stimulation. Likewise, $\mathrm{GABA}_{\mathrm{A}}$ receptor blockade allows NMDA receptor activation to enhance after-depolarizations.

To evaluate the effect of drug treatments on interlaminar spread, we plotted distributions along a dorsoventral path extending from the dorsal limit of the SC, through the SGI, to a depth of $\sim 1 \mathrm{~mm}$. In the monkey, a depth of $1 \mathrm{~mm}$ from the surface of the SC is in the upper SGI, whereas in the rat $1 \mathrm{~mm}$ is in the lower SGI and even deeper (stratum griseum profundum). Responses were compared for control, NBQX, NBQX + TTX, $\mathrm{GABA}_{\mathrm{A}}$ receptor antagonists, and $\mathrm{GABA}_{\mathrm{A}}$ receptor antagonists + APV. For SGS stimulation, the initial-spike amplitude was maximal in the SGS and appeared to decay $\sim 400-500 \mu \mathrm{m}$ into the SGI (Fig. 14Ai, black line). SGI stimulation also evoked initialspikes with maximal amplitudes in the SGS $(\sim 400-500 \mu \mathrm{m}$ from the stimulation site), but showed little spread ventral to the site of stimulation (Fig. 14Bi, black line). Again, normalization to the maximum amplitude can obscure the spread of signal into the deeper layers, but the general trends of interlaminar spread can be easily visualized. Plots of after-depolarizations showed similar trends to initial-spike patterns for both stimulation sites (Fig. 14Aii,Bii, black lines). Furthermore, we plotted non-normalized signal amplitudes to examine more closely the patterns of signal spread resulting from stimulation in SGS and SGI (Fig. 14Ci,Cii). These plots show that, with SGS stimulation, the signals spread from the SGS into the SGI ventrally to a depth of $\sim 800 \mu \mathrm{m}$. 


\section{Superficial Layer Stimulation:}

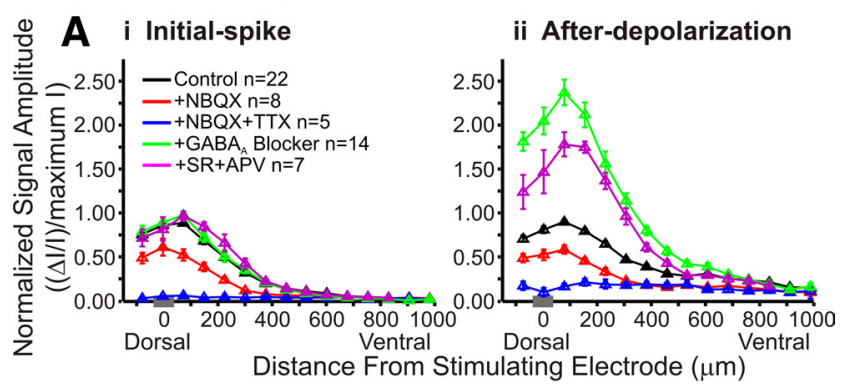

Intermediate Layer Stimulation:

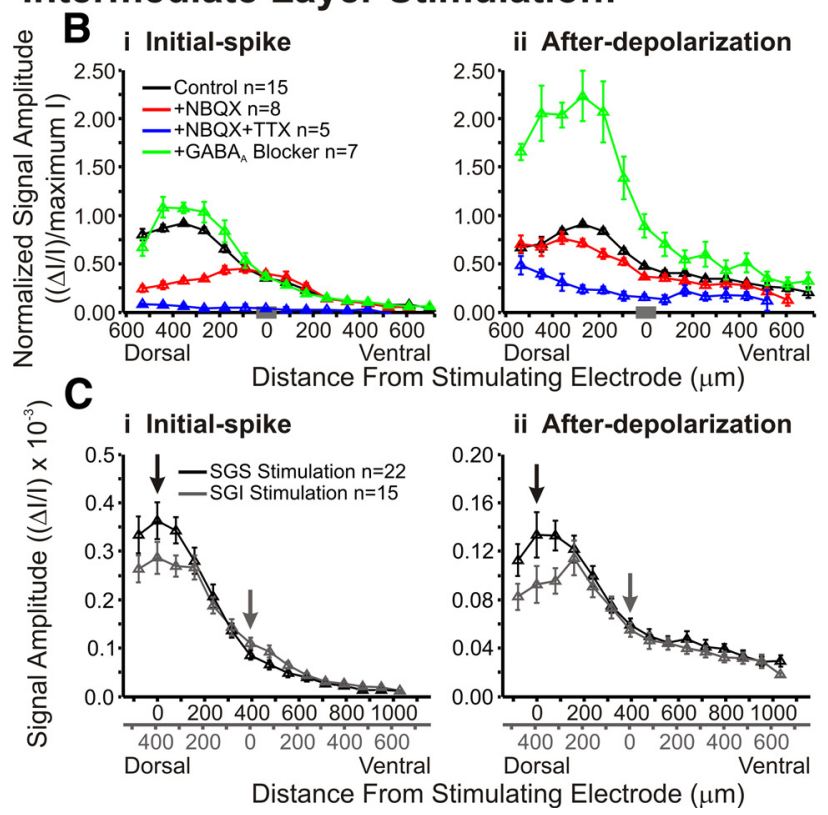

Figure 14. Pharmacological agents alter the dorsoventral distribution of responses within the SC. $\boldsymbol{A}$, Normalized signal amplitude is plotted against dorsoventral distance from the stimulating electrode for initial-spike (i, $0-10 \mathrm{~ms}$ ) and after-depolarization (ii, $20-160 \mathrm{~ms}$ ) following SGS stimulation. Vertical lines represent SE. The data were normalized to the maximum amplitude of control (predrug) signal. Data are plotted for control (black; SGS stimulus, $N=22$; SGI stimulus, $N=15$ ), after addition of NBQX (red; $S G S$ stimulus, $N=8 ; S G I$ stimulus, $N=8$ ), after addition of NBQX and TTX (blue; $S G S$ stimulus, $N=5$; $S G I$ stimulus, $N=5$ ), after application of $G A B A_{A}$ receptor blocker (green; $S G S$ stimulus, $N=14$; $S G I$ stimulus, $N=7$ ), and after application of $G A B A_{A}$ receptor blocker $(S R)$ and $A P V$ (magenta; $S G S$ stimulus, $N=7$ ). The data were binned to provide 15 location points. The gray bar on the $x$-axis in each panel indicates the zero distance bin. $\boldsymbol{B}$, Same as in $\boldsymbol{A}$ following $\mathrm{SGI}$ stimulation. Note that APV was not applied in SGI stimulation experiments. C, Comparison of non-normalized signal amplitude $(\Delta \mathrm{l} / \mathrm{I})$ from SGS stimulation (black, $N=22$ ) and SGI stimulation (gray, $N=15$ ) for initial-spike (i) and after-depolarization (ii). Data were binned into 18 discrete location points. Arrows indicate the zero distance bins for each type of stimulation. Duel $x$-axes are shown with the relative distances from stimulating electrode.

Stimulation in SGI evoked signals that spread dorsally into the SGS $\sim 500 \mu \mathrm{m}$ (reaching the dorsal boundary of the SC). It is interesting to note that although the highest amplitude signals reside in the superficial layers (SGS and SO) for either type of stimulation, SGI stimulation produces lower amplitude signals at the dorsal border of the SC than does SGS stimulation. In some cases, the areas with the largest responses to SGI stimulation fall at the border of the SGS and SO, which is slightly more ventral than what is observed with SGS stimulation (Figs. 3, 6). This is consistent with the recruitment of different populations of neurons in the superficial layers by stimulation in the SGS versus the SGI.
Following SGS stimulation, NBQX reduced the amplitude of the initial-spike and after-depolarization along the entire dorsoventral path (Fig. 14Ai,Aii, black and red lines). As with intralaminar spread, TTX eliminated almost all of the residual NBQX-insensitive interlaminar spread of both initial-spikes and after-depolarizations (Fig. 14Ai,Aii, blue lines). Additionally, these plots revealed interesting spatial variations in how NBQX inhibited responses to SGI stimulation. NBQX strongly blocked the spread of initial-spikes dorsally into the SGS but failed to block initial-spikes locally within the layer of stimulation (Figs. $13 \mathrm{Di}, 14 \mathrm{Bi}$, black and red lines). Therefore, the dorsal spread of the initial-spike from the SGI into the SGS depended primarily on AMPA receptors, but the ventral spread into deeper layers of the SGI depended primarily on voltage-gated $\mathrm{Na}^{+}$channels (Fig. $14 B i$, black, red, and blue lines). Furthermore, NBQX had little effect on the after-depolarization evoked by SGI stimulation along the entire dorsoventral path (Fig. $14 \mathrm{Bii}$ ). This is in contrast to the after-depolarization evoked by SGS stimulation, which was blocked by NBQX over the entire path (Fig. 14Aii). These results indicate that stimulation in each of these sites activates different circuitry and, moreover, suggest the existence of an excitatory interlaminar pathway originating in the SGI and extending dorsally into the SGS.

These interlaminar plots also show that the effect of $\mathrm{GABA}_{\mathrm{A}}$ receptor blockade on the initial-spike was weak throughout the $\mathrm{SC}$ (Fig. 14Ai,Bi, black and green lines), but that afterdepolarizations were enhanced by $\mathrm{GABA}_{\mathrm{A}}$ receptor blockade throughout the SC (Fig. 14Aii,Bii, black and green lines). Following SGS stimulation and $\mathrm{GABA}_{\mathrm{A}}$ receptor block, the afterdepolarization was reduced by APV (Fig. 14Aii, magenta line). Note that APV was not tested in SGI stimulation experiments. Supplemental Figure 1 (available at www.jneurosci.org as supplemental material) shows a three-dimensional plot of the effect of $\mathrm{GABA}_{\mathrm{A}}$ receptor blockers on interlaminar spread. Each vertical line in the three-dimensional plot represents a two-dimensional interlaminar plot at a given time, and is thus related to the two-dimensional plots in Figure 14 showing the maximum signal within specific time frames. These graphs, in addition to the intralaminar plots shown in Figure 13, indicate a strong and widespread role for $\mathrm{GABA}_{\mathrm{A}}$ receptors in limiting the after-depolarization.

\section{Discussion}

We conducted experiments using the voltage-sensitive absorbance dye RH482 to image electrically evoked responses in slices of rat SC. RH482 preferentially targets the membranes of neurons (Kojima et al., 1999), and absorbance of light by RH482 varies linearly with voltage, responding with microsecond kinetics (Salzberg, 1989). These characteristics allow us to image changes in membrane potential accompanying action potentials and fast excitatory synaptic potentials. Voltage imaging also allows us to use tissue from animals between 3 and 8 weeks old. Therefore, we can compare the circuitry in juvenile animals with that of adults. This is an advantage over many other techniques that must be performed in slices from young animals.

The results presented here provide the first high temporal and spatial resolution measurements of activity within slices of the SC, enabling us to follow the spread and dynamics of electrical activity at the population level within $\sim 67 \mu \mathrm{m}$ domains. We found that a single-stimulus pulse in SGS elicited responses extending up to distances of $\sim 500 \mu \mathrm{m}$ both medially and laterally from the site of stimulation. Responses also spread ventrally into the intermediate and deep layers of the SC. In contrast, stimula- 
tion in the SGI resulted in a restricted pattern of mediolateral spread to distances of only $\sim 250 \mu \mathrm{m}$ in either direction. Interestingly, stimulation of the SGI resulted in optical signals that first spread dorsally into the superficial layers and then spread medially and laterally within the SGS over distances of $\sim 600 \mu \mathrm{m}$. The spread of optical signals evoked by both SGS and SGI stimulation was enhanced by blockade of $\mathrm{GABA}_{\mathrm{A}}$ receptors and was reduced by blockade of glutamate receptors. Together, the results indicate that excitation arising from a single pulse travels extensively both within and between the layers of the SC, and much of this spread is mediated by synaptic connections. Here we discuss the results as they relate to previous work in the SC in vitro, and then address possible relationships to the in vivo activity of SC neurons.

\section{Relationship to previous in vitro results}

Electrical stimulation anywhere in the SC evoked optical signals with two distinct temporal components: a short latency initialspike and long latency after-depolarization. Similar twocomponent optical responses have been reported in the optic tectum of lower vertebrates, suggesting that the electrical repertoire of SC neurons and circuits are evolutionarily conserved (Vanegas, 1984; Kinoshita et al., 2002). The optical signals represent a sum of depolarizing and hyperpolarizing potentials from neurons contained within $\sim 67 \mu \mathrm{m}$ diode fields, with excitation dominating despite the strong inhibitory circuitry of the SC in vitro (Mize, 1992; Behan et al., 2002; Saito and Isa, 2003). Experiments with glutamate and $\mathrm{GABA}_{\mathrm{A}}$ receptor antagonists indicate that both excitation and inhibition contribute to the optical signals.

Early anatomical and physiological studies produced little evidence in support of an interlaminar pathway from the superficial SC to the intermediate SC (Sprague, 1975; Edwards, 1980; Mays and Sparks, 1980). However, more recent studies clearly demonstrate a ventrally directed excitatory pathway (Mooney et al., 1988b; Behan and Appell, 1992; Lee and Hall, 1995; Lee et al., 1997; Isa et al., 1998). Our results support the more recent finding of functional linkages connecting the SC layers, showing that local stimulation of the SGS results in both intralaminar and interlaminar spread of initial-spikes and after-depolarizations.

A dorsally directed excitatory pathway is hypothesized to exist in monkey SC based on behavioral and electrophysiological findings (Wurtz and Mohler, 1976). However, evidence for this pathway remains elusive. A recent study identified a dorsally directed pathway from SGI to SGS, but this pathway was inhibitory (Lee et al., 2007). The present work offers the first evidence for a dorsally directed excitatory pathway. Although we cannot completely rule out the possibility that the spread of signal from SGI to SGS is mediated by antidromic activation of axons arising from SGS and SO neurons, several pieces of evidence make this less likely. First, the propagation time for signals to travel into the SGS following SGI stimulation was variable, whereas antidromic activation is characterized by short, fixed latencies (Bishop et al., 1962). However, the slow velocity of initial-spike reported here was comparable to that reported for fine, unmyelinated axons (Zhang et al., 2007). Consequently, antidromic activation of fine fibers remains a possibility. Second, we found that signal spread from SGI to the SGS was blocked by AMPA receptor antagonists. Antidromic activation should be insensitive to glutamate receptor blockers. However, we cannot rule out the possibility that an excitatory interneuron mediated signal spread. Also, because corticotectal axons targeting the SGS arise from the brachium of the rostral colliculus, arborize in the SGS, and seem to avoid the SGI, we do not think that our stimulation is orthodromically activating these input fibers (Plummer and Behan, 1992) (M. Bickford, personal communication). Future experiments using focal application of glutamate will provide a more direct test of the existence of a dorsally directed excitatory pathway suggested by the present work.

Our results also reveal the activity of intralaminar circuitry in the SC. Signals evoked by stimulation in the SGS spread medially and laterally, likely through the activation of horizontal cells and wide-field vertical cells. Horizontal cells have dendritic trees that extend 200-1000 $\mu \mathrm{m}$ within the SGS and wide-field vertical cells have dendrites extending up to $2 \mathrm{~mm}$ (Langer and Lund, 1974; Mooney et al., 1988a; Endo et al., 2003). Spread within the SGS likely extends beyond the activation of single neurons because glutamate receptor blockers greatly reduce intralaminar spread. Whole-cell patch-clamp reports indicate that horizontal cells receive an initial excitatory input as well as a second inhibitory synaptic input (Langer and Lund, 1974; Özen et al., 2000).

Stimulation of the SGI also resulted in mediolateral spread, which was more extensive within the SGS than spread seen with SGS stimulation. This dissimilarity provides compelling evidence that stimulation in different SC laminae activates distinct circuits. One possible explanation for this is that SGI stimulation activates horizontal cells less effectively than SGS stimulation. Since SC horizontal cells are fast-spiking inhibitory interneurons (Endo et al., 2003), weaker activation of these cells could enhance mediolateral spread. A second possibility is that SGI stimulation more effectively activates wide-field vertical cells. Experiments combining whole-cell patch-clamp recording with voltage imaging will address these possibilities.

A second noteworthy difference between response patterns from the two stimulation sites was that responses to SGI stimulation were more restricted at the site of stimulation when compared with responses following SGS stimulation. The restricted locus of activity in SGI is consistent with deoxyglucose imaging results obtained in monkeys performing saccades (Moschovakis et al., 2001). We were somewhat surprised by this result because the concentration of inhibitory $\mathrm{GABA}_{\mathrm{A}}$ receptors is higher in SGS than in SGI (Mize, 1992; Behan et al., 2002). Our results suggest that, regardless of the neuronal cell type underlying the signal spread, the connectivity within the SC differs considerably between SGI and SGS.

Responses of neurons from whole-cell patch-clamp recordings are consistent with the hypothesis that the summed activity of narrow-field vertical cells, wide-field vertical cells, and horizontal cells underlie the two temporal components of activity we observe. Our control experiments indicated that neurons underlie the observed signal because glutamate transporter blockers that reduce responses in glia (Kojima et al., 1999) failed to alter our signals. Initial-spikes rose and fell within $10 \mathrm{~ms}$, whereas after-depolarizations arose after $10 \mathrm{~ms}$ and lasted 200-300 ms. Both narrow-field and wide-field neurons produce one action potential followed by a slow depolarization in response to SGS stimulation (Özen et al., 2000). This response profile may underlie the initial-spike. Narrow-field, wide-field, and horizontal cells can also produce prolonged bursts lasting up to a few hundred milliseconds and this asynchronous activity may underlie the after-depolarization.

The after-depolarization could reflect activation by recurrent collaterals arising from premotor cell axons (Mooney et al., 1988b; Moschovakis et al., 1988; Hall and Lee, 1997; Pettit et al., 1999) or intrinsic (circuitry-independent) activity of voltagegated channels. It is not possible to determine the relative contributions from these two sources with our data. However, the after-depolarization is shaped by $\mathrm{GABA}_{\mathrm{A}}$ receptor mediated 
inhibition and it is likely that prolonged bursting by GABAergic horizontal cells curtails prolonged bursting of narrow-field and wide-field vertical cells. Previous studies have shown enhanced excitatory responses in the SC following $\mathrm{GABA}_{\mathrm{A}}$ receptor blockade (Isa et al., 1998; Özen et al., 2000; Saito and Isa, 2003; Kaneda et al., 2008; Phongphanphanee et al., 2008). Our results are consistent with these results, but indicate that each temporal component of the optical signal is modulated by $\mathrm{GABA}_{\mathrm{A}}$ receptors differently. The present results show that $\mathrm{GABA}_{\mathrm{A}}$ receptor blockade increases the after-depolarization approximately twofold throughout the SC, while increasing the initial-spike only slightly. The speed of the initial-spike leaves less time for the inhibitory action from synaptically activated horizontal cells. Regardless, the after-depolarization represents population activity from excitatory and inhibitory neurons throughout the SC.

\section{Relationship to previous in vivo results}

The primary motive for conducting these in vitro experiments is to deepen our understanding of in vivo work on the SC and its role in controlling sensorimotor integration and eye movements. Extracellular recordings from SC neurons of monkeys reveal a robust initial action-potential discharge associated with the onset of a visual stimulus, followed by a tonic discharge at a reduced level (Munoz and Wurtz, 1995; McPeek and Keller, 2002; Li and Basso, 2005, 2008). This tonic discharge has a long duration, generally lasting until a cue is provided to initiate a saccade (Glimcher and Sparks, 1992). If electrical stimulation of the SGS in vitro mimics the onset of a visual stimulus used to elicit behavior in vivo, then the two-component response we see in vitro may be a population response similar to that measured as a twocomponent response in vivo. Voltage imaging in vitro also has the advantage of detecting subthreshold voltage changes (EPSPs) that contribute to SC activity but are not detected by extracellular electrodes in vivo. These subthreshold signals may be relevant to integration mechanisms used by the SC to select particular targets for saccades (Glimcher and Sparks, 1992; Basso and Wurtz, 1998; Krauzlis and Dill, 2002; McPeek and Keller, 2002, 2004; Carello and Krauzlis, 2004). Neurons in the rodent SC are well characterized physiologically and anatomically, but their relationship to behavior is unknown. In contrast, the physiological properties of monkey SC neurons have been behaviorally characterized, but detailed physiology and morphology remains unknown. In vitro studies such as ours could ultimately provide a critical link between the response profiles measured in vivo and the biophysical properties of the underlying circuits. For example, one prediction from the present results is that introduction of $\mathrm{GABA}_{\mathrm{A}}$ receptor blockers into monkey $\mathrm{SC}$ will enhance the discharge properties of SGS visual tonic neurons as well as SGI buildup neurons. Thus, these in vitro experiments generate hypotheses that we can test in vivo.

Note added in proof. Exemplar tissue provided by M. Bickford shows evidence of cortical afferents to the superior colliculus entering through the optic tract.

\section{References}

Basso MA, Wurtz RH (1998) Modulation of neuronal activity in superior colliculus by changes in target probability. J Neurosci 18:7519-7534.

Behan M, Appell PP (1992) Intrinsic circuitry in the cat superior colliculus: projections from the superficial layers. J Comp Neurol 315:230-243.

Behan M, Steinhacker K, Jeffrey-Borger S, Meredith MA (2002) Chemoarchitecture of GABAergic neurons in the ferret superior colliculus. J Comp Neurol 452:334-359.

Bishop PO, Burke W, Davis R (1962) Single-unit recording from antidromically activated optic radiation neurones. J Physiol 162:432-450.
Carello CD, Krauzlis RJ (2004) Manipulating intent: evidence for a causal role of the superior colliculus in target selection. Neuron 43:575-583.

Chalupa LM, Williams RW (2008) Eye, retina, and visual system of the mouse. Cambridge, MA: MIT.

Chang PY, Jackson MB (2006) Heterogeneous spatial patterns of long-term potentiation in rat hippocampal slices. J Physiol 576:427-443.

Chelazzi L, Rossi F, Tempia F, Ghirardi M, Strata P (1989) Saccadic eye movements and gaze holding in the head-restrained pigmented rat. Eur J Neurosci 1:639-646.

Chevalier G, Deniau JM (1990) Disinhibition as a basic process in the expression of striatal functions. Trends Neurosci 13:277-280.

Chevalier G, Vacher S, Deniau JM, Desban M (1985) Disinhibition as a basic process in the expression of striatal functions. I. The striato-nigral influence on tecto-spinal/tecto-diencephalic neurons. Brain Res 334:215-226.

Dean P, Redgrave P, Westby GW (1989) Event or emergency?: Two response systems in the mammalian superior colliculus. Trends Neurosci 12:137-147.

Edwards S (1980) The deep cell layers of the superior colliculus: their retirular characteristics and structural organization. In: The reticular formation revisted (Hobson JA, Brazier MAB, eds), pp 193-209. New York: Raven.

Endo T, Yanagawa Y, Obata K, Isa T (2003) Characteristics of GABAergic neurons in the superficial superior colliculus in mice. Neurosci Lett 346:81-84

Fuller JH (1985) Eye and head movements in the pigmented rat. Vision Res 25:1121-1128.

Glimcher PW, Sparks DL (1992) Movement selection in advance of action in the superior colliculus. Nature 355:542-545.

Groh JM (2001) Converting neural signals from place codes to rate codes. Biol Cybern 85:159-165.

Hall WC, Lee P (1993) Interlaminar connections of the superior colliculus in the tree shrew. I. The superficial gray layer. J Comp Neurol 332:213-223.

Hall WC, Lee P (1997) Interlaminar connections of the superior colliculus in the tree shrew. III. The optic layer. Vis Neurosci 14:647-661.

Hanes DP, Wurtz RH (2001) Interaction of the frontal eye field and superior colliculus for saccade generation. J Neurophysiol 85:804-815.

Isa $\mathrm{T}$ (2002) Intrinsic processing in the mammalian superior colliculus. Curr Opin Neurobiol 12:668-677.

Isa T, Hall WC (2009) Exploring the superior colliculus in vitro. J Neurophysiol 102:2581-2593.

Isa T, Endo T, Saito Y (1998) The visuo-motor pathway in the local circuit of the rat superior colliculus. J Neurosci 18:8496-8504.

Kaneda K, Isa K, Yanagawa Y, Isa T (2008) Nigral inhibition of GABAergic neurons in mouse superior colliculus. J Neurosci 28:11071-11078.

Kennedy MC (1984) Development and structure of the lamprey optic tectum. In: Comparative neurology of the optic tectum (Vanegas $\mathrm{H}$, ed). New York: Plenum.

Kim B, Basso MA (2008) Saccade target selection in the superior colliculus: a signal detection theory approach. J Neurosci 28:2991-3007.

Kim B, Basso MA (2010) A probabilistic strategy for understanding action selection. J Neurosci 30:2340-2355.

Kinoshita M, Ueda R, Kojima S, Sato K, Watanabe M, Urano A, Ito E (2002) Multiple-site optical recording for characterization of functional synaptic organization of the optic tectum of rainbow trout. Eur J Neurosci $16: 868-876$.

Kojima S, Nakamura T, Nidaira T, Nakamura K, Ooashi N, Ito E, Watase K, Tanaka K, Wada K, Kudo Y, Miyakawa H (1999) Optical detection of synaptically induced glutamate transport in hippocampal slices. J Neurosci 19:2580-2588.

Krauzlis R, Dill N (2002) Neural correlates of target choice for pursuit and saccades in the primate superior colliculus. Neuron 35:355-363.

Langer TP, Lund RD (1974) The upper layers of the superior colliculus of the rat: a Golgi study. J Comp Neurol 158:405-435.

Lee C, Rohrer WH, Sparks DL (1988) Population coding of saccadic eye movements by neurons in the superior colliculus. Nature 332:357-360.

Lee P, Hall WC (1995) Interlaminar connections of the superior colliculus in the tree shrew. II. Projections from the superficial gray to the optic layer. Vis Neurosci 12:573-588.

Lee P, Hall WC (2006) An in vitro study of horizontal connections in the intermediate layer of the superior colliculus. J Neurosci 26:4763-4768.

Lee PH, Helms MC, Augustine GJ, Hall WC (1997) Role of intrinsic synap- 
tic circuitry in collicular sensorimotor integration. Proc Natl Acad Sci U S A 94:13299-13304.

Lee PH, Schmidt M, Hall WC (2001) Excitatory and inhibitory circuitry in the superficial gray layer of the superior colliculus. J Neurosci 21:8145-8153.

Lee PH, Sooksawate T, Yanagawa Y, Isa K, Isa T, Hall WC (2007) Identity of a pathway for saccadic suppression. Proc Natl Acad Sci USA 104:6824-6827.

Li X, Basso MA (2005) Competitive stimulus interactions within single response fields of superior colliculus neurons. J Neurosci 25:11357-11373.

Li X, Basso MA (2008) Preparing to move increases the sensitivity of superior colliculus neurons. J Neurosci 28:4561-4577.

Liu J, Luo F (1996) Physiological properties of neurons in superficial layers of superior colliculus of rabbits. Sci China C Life Sci 39:406-417.

Mays LE, Sparks DL (1980) Dissociation of visual and saccade-related responses in superior colliculus neurons. J Neurophysiol 43:207-232.

McHaffie JG, Stein BE (1982) Eye movements evoked by electrical stimulation in the superior colliculus of rats and hamsters. Brain Res 247:243-253.

McIlwain JT (1991) Distributed spatial coding in the superior colliculus: a review. Vis Neurosci 6:3-13.

McPeek RM, Keller EL (2002) Saccade target selection in the superior colliculus during a visual search task. J Neurophysiol 88:2019-2034.

McPeek RM, Keller EL (2004) Deficits in saccade target selection after inactivation of superior colliculus. Nat Neurosci 7:757-763.

Mize RR (1992) The organization of GABAergic neurons in the mammalian superior colliculus. Prog Brain Res 90:219-248.

Mooney RD, Nikoletseas MM, Ruiz SA, Rhoades RW (1988a) Receptivefield properties and morphological characteristics of the superior collicular neurons that project to the lateral posterior and dorsal lateral geniculate nuclei in the hamster. J Neurophysiol 59:1333-1351.

Mooney RD, Nikoletseas MM, Hess PR, Allen Z, Lewin AC, Rhoades RW (1988b) The projection from the superficial to the deep layers of the superior colliculus: an intracellular horseradish peroxidase injection study in the hamster. J Neurosci 8:1384-1399.

Moschovakis AK, Karabelas AB, Highstein SM (1988) Structure-function relationships in the primate superior colliculus. I. Morphological classification of efferent neurons. J Neurophysiol 60:232-262.

Moschovakis AK, Gregoriou GG, Savaki HE (2001) Functional imaging of the primate superior colliculus during saccades to visual targets. Nat Neurosci 4:1026-1031.

Munoz DP, Wurtz RH (1995) Saccade-related activity in monkey superior colliculus. I. Characteristics of burst and buildup cells. J Neurophysiol 73:2313-2333.

Ottes FP, Van Gisbergen JA, Eggermont JJ (1986) Visuomotor fields of the superior colliculus: a quantitative model. Vision Res 26:857-873.

Özen G, Augustine GJ, Hall WC (2000) Contribution of the superficial layer neurons to premotor bursts in the superior colliculus. J Neurophysiol 84:460-471.

Pettit DL, Helms MC, Lee P, Augustine GJ, Hall WC (1999) Local excitatory circuits in the intermediate gray layer of the superior colliculus. J Neurophysiol 81:1424-1427.

Phongphanphanee P, Kaneda K, Isa T (2008) Spatiotemporal profiles of field potentials in mouse superior colliculus analyzed by multichannel recording. J Neurosci 28:9309-9318.

Plummer KL, Behan M (1992) Postnatal development of the corticotectal projection in cats. J Comp Neurol 315:178-199.

Port NL, Wurtz RH (2003) Sequential activity of simultaneously recorded neurons in the superior colliculus during curved saccades. J Neurophysiol 90:1887-1903.

Quaia C, Aizawa H, Optican LM, Wurtz RH (1998) Reversible inactivation of monkey superior colliculus: II. Maps of saccadic deficits. J Neurophysiol 79:2097-2110.

Robinson DA (1972) Eye movements evoked by collicular stimulation in the alert monkey. Vision Res 12:1795-1808.

Saito Y, Isa T (2003) Local excitatory network and NMDA receptor activation generate a synchronous and bursting command from the superior colliculus. J Neurosci 23:5854-5864.

Saito Y, Isa T (2005) Organization of interlaminar interactions in the rat superior colliculus. J Neurophysiol 93:2898-2907.

Sakatani T, Isa T (2004) PC-based high-speed video-oculography for measuring rapid eye movements in mice. Neurosci Res 49:123-131.

Sakatani T, Isa T (2007) Quantitative analysis of spontaneous saccade-like rapid eye movements in C57BL/6 mice. Neurosci Res 58:324-331.

Salzberg BM (1989) Optical recording of voltage changes in nerve terminals and in fine neuronal processes. Annu Rev Physiol 51:507-526.

Schiller PH, Koerner F (1971) Discharge characteristics of single units in superior colliculus of the alert rhesus monkey. J Neurophysiol 34: 920-936.

Sparks DL (1975) Response properties of eye movement-related neurons in the monkey superior colliculus. Brain Res 90:147-152.

Sparks DL (1978) Functional properties of neurons in the monkey superior colliculus: coupling of neuronal activity and saccade onset. Brain Res 156:1-16.

Sparks DL (1986) Translation of sensory signals into commands for control of saccadic eye movements: role of primate superior colliculus. Physiol Rev 66:118-171.

Sprague JM (1975) Mammalian tectum: intrinsic organization, afferent inputs, and integrative mechanisms: anatomical substrate. Neurosci Res Program Bull 13:204-213.

Van Gisbergen JA, Van Opstal AJ, Tax AA (1987) Collicular ensemble coding of saccades based on vector summation. Neuroscience 21:541-555.

Vanegas H, ed (1984) Comparative neurology of the optic tectum. New York: Plenum.

Wu JY, Cohen LB (1993) Fast multisite optical measurements of membrane potential. In: Fluorescent and luminescent probes for biological activity (Mason WT, ed), pp 389-404. London: Academic.

Wurtz RH, Goldberg ME (1972) Activity of superior colliculus in behaving monkey. III. Cells discharging before eye movements. J Neurophysiol 35:575-586.

Wurtz RH, Mohler CW (1976) Organization of monkey superior colliculus: enhanced visual response of superficial layer cells. J Neurophysiol 39:745-765.

Zhang Z, Klyachko V, Jackson MB (2007) Blockade of phosphodiesterase type 5 enhances rat neurohypophysial excitability and electrically evoked oxytocin release. J Physiol 584:137-147. 